\title{
Spinal Cord Injury Causes Brain Inflammation Associated with Cognitive and Affective Changes: Role of Cell Cycle Pathways
}

\author{
Junfang Wu, ${ }^{\star}$ Zaorui Zhao, ${ }^{\star}$ Boris Sabirzhanov, ${ }^{\circ}$ Bogdan A. Stoica, Alok Kumar, Tao Luo, Jacob Skovira, \\ and Alan I. Faden \\ Department of Anesthesiology and Center for Shock, Trauma and Anesthesiology Research (STAR), University of Maryland School of Medicine, Baltimore, \\ Maryland 21201
}

\begin{abstract}
Experimental spinal cord injury (SCI) causes chronic neuropathic pain associated with inflammatory changes in thalamic pain regulatory sites. Our recent studies examining chronic pain mechanisms after rodent SCI showed chronic inflammatory changes not only in thalamus, but also in other regions including hippocampus and cerebral cortex. Because changes appeared similar to those in our rodent TBI models that are associated with neurodegeneration and neurobehavioral dysfunction, we examined effects of mouse SCI on cognition, depressive-like behavior, and brain inflammation. SCI caused spatial and retention memory impairment and depressive-like behavior, as evidenced by poor performance in the Morris water maze, $Y$-maze, novel objective recognition, step-down passive avoidance, tail suspension, and sucrose preference tests. SCI caused chronic microglial activation in the hippocampus and cerebral cortex, where microglia with hypertrophic morphologies and M1 phenotype predominated. Stereological analyses showed significant neuronal loss in the hippocampus at 12 weeks but not $8 \mathrm{~d}$ after injury. Increased cell-cycle-related gene (cyclins A1, A2, D1, E2F1, and PCNA) and protein (cyclin D1 and CDK4) expression were found chronically in hippocampus and cerebral cortex. Systemic administration of the selective cyclin-dependent kinase inhibitor CR8 after SCI significantly reduced cell cycle gene and protein expression, microglial activation and neurodegeneration in the brain, cognitive decline, and depression. These studies indicate that SCI can initiate a chronic brain neurodegenerative response, likely related to delayed, sustained induction of M1-type microglia and related cell cycle activation, which result in cognitive deficits and physiological depression.
\end{abstract}

Key words: brain; cognition; depression; inflammation; neurodegeneration; spinal cord injury

\section{Introduction}

The chronic effects of spinal cord injury (SCI) have focused on sensorimotor dysfunction and hyperpathic pain. Clinical study has suggested potential cognitive changes based upon patient self-reporting of postmorbid conditions (Murray et al., 2007). The concept that SCI causes changes in brain has largely been restricted to alterations in afferent and efferent pathways. However, supratentorial changes have been reported in localized brain regions associated with pain modulation after SCI-induced hy-

Received Dec. 6, 2013; revised June 18, 2014; accepted July 11, 2014.

Author contributions: J.W. and A.I.F. designed research; J.W., Z.Z., B.S., A.K., T.L., and J.S. performed research;

J.W., Z.Z., B.S., and B.A.S. analyzed data; J.W. and A.I.F. wrote the paper.

This work was supported by the National Institutes of Health (Grants R01 NS054221 and R01 NR013601 to A.I.F. and Grant R21 NR014053 to J.W.) and by startup funds from the Department of Anesthesiology, University of Maryland School of Medicine, Baltimore, MD (J.W.). We thank Kelsey Guanciale, Katherine Cardiff, Angela Pan, and Shuxin Zhao for expert technical support.

The authors declare no competing financial interests.

*J.W. and Z.Z. contributed equally to this work.

Correspondence should be addressed to Dr. Junfang Wu, Department of Anesthesiology and Center for Shock, Trauma and Anesthesiology Research (STAR), National Study Center for Trauma and EMS, University of Maryland, School of Medicine, Bressler Research Building, 655 W. Baltimore Street, Room \#6-009, Baltimore, MD 21201. E-mail:jwu@anes.umm.edu.

DOI:10.1523/JNEUROSCI.5110-13.2014

Copyright $\odot 2014$ the authors $\quad 0270-6474 / 14 / 3410989-18 \$ 15.00 / 0$ peresthesia, including chronic inflammatory changes associated with plasticity or electrophysiological alterations (Hains et al., 2005; Hubscher and Johnson, 2006; Zhao et al., 2007; KnerlichLukoschus et al., 2011; Yoon et al., 2013). In our own recent studies examining mechanisms of SCI-induced hyperpathia in rodent models, we observed sustained neuroinflammation not only in brain regions regulating pain sensation (Wu et al., 2013b), but also more diffusely in cortex, thalamus, and hippocampus. Because the degree and pattern of changes was similar to those associated with the chronic neurodegeneration observed after traumatic brain injury (TBI) in rodents (Kumar and Loane, 2012), we initiated an independent study to determine whether brain neurodegeneration and functional neurological correlates occur after isolated thoracic SCI.

Assessments of neuronal changes in the brain after SCI have been focused on the motor cortex and are controversial, with conclusions ranging from no cell death to extensive retrograde degeneration. Some studies found no changes in the motor cortex and the medullary pyramid after SCI (Mason et al., 2003; Crawley et al., 2004; Nielson et al., 2010). Others have identified significant neuropathological changes based on counts of neurons in the cortex; for example, retrogradely labeled cortical motoneurons (Feringa and Vahlsing, 1985; Giehl and Tetzlaff, 1996; 
Hammond et al., 1999; Bonatz et al., 2000; Hains et al., 2003; Klapka et al., 2005) and shrinkage of the cell bodies (Ganchrow and Bernstein, 1985; Merline and Kalil, 1990; Wannier et al., 2005; Nielson et al., 2010; Nielson et al., 2011). One of the limitations of all of these studies is that they were performed over poorly defined widespread areas of the cerebral cortex and, most importantly, did not involve rigorous quantitative assessment techniques. In contrast, our study used stereology techniques with computer-driven, random, systematic sampling to provide unbiased and quantitative data for cell counting.

Substantial experimental evidence, much from our laboratory, indicates that, in postmitotic neurons, cell cycle activation (CCA) is associated with neuronal cell death, whereas in microglia or astrocytes, it leads to cell proliferation and activation $(\mathrm{Wu}$ et al., 2011). We have identified chronic CCA in the posterior thalamic nucleus after rat contusion SCI, which was associated with hyperesthesia, increased neuronal excitability, and microglial activation (Wu et al., 2013b). Increased microglial activation, chemokine levels, and CCA were also found in the ventral posteriolateral nucleus of thalamus (Wu et al., 2013b); these were previously implicated in hyperpathic responses after SCI (Zhao et al., 2007). In the present study, we examined more broadly the effects of impact SCI in mice on cognitive and affective function, brain inflammation, CCA, and neuropathology; we also examined the effect of early cell cycle inhibition on these outcomes.

\section{Materials and Methods}

Mouse spinal cord contusion and drug administration. Adult male C57BL/6J mice (22-26 g; The Jackson Laboratory) were anesthetized with isoflurane and received T9 spinal contusions using the Infinite Horizon Spinal Cord Impactor (Precision Systems and Instrumentation) with a force of $60 \mathrm{kdyn}$, a moderate injury (Wu et al., 2013a). Bladders were manually expressed twice daily until a reflex bladder was established (7-14 d after SCI). After SCI, mice were assigned to a treatment group according to a randomized block experimental design. The number of mice at various time points in each study is indicated in the figure legends. All SCI animals were assessed at $1 \mathrm{~d}, 8 \mathrm{~d}$, and 3 months after injury by the same surgeon and at the same period of time. All procedures were performed under protocols approved by the University of Maryland School of Medicine Animal Care and Use Committee.

A potent, selective cyclin-dependent kinase (CDK) inhibitor CR8 (a second-generation roscovitine analog) was used for the inhibition of cell cycle pathway. (R)-CR8 (\#3605; Tocris Bioscience) was reconstituted in $0.9 \%$ saline and administered intraperitoneally with $1 \mathrm{mg} / \mathrm{kg}$ as a final dosage given once daily beginning $3 \mathrm{~h}$ after injury and continuing for $7 \mathrm{~d}$. The vehicle control was $0.9 \%$ saline administered intraperitoneally. The dose of CR8 was based upon prior investigations in rat SCI model (Wu et al., 2012a; Wu et al., 2012c; Wu et al., 2013b). To minimize stress and fatigue, a battery of behavioral tests were divided into two studies. Study 1 included the Morris water maze (MWM), tail suspension (TS), open field (OF), and novel object recognition (NOR) tests. A separate cohort of mice in Study 2 was for Y-maze spontaneous alternation, step-down passive avoidance (SDPA), and sucrose preference (SP) tests. The timeline of the experimental design is shown in Figure 1.

Motor function evaluation. Mice were tested for hindlimb function in OF locomotion on day 1 after injury and weekly thereafter for up to 8 weeks using the Basso mouse scale (BMS) (Basso et al., 2006). The spontaneous locomotor activity was evaluated on week 10 after injury in the OF (Zhao et al., 2012). Mice were individually placed in a corner facing the wall of the OF chamber $(22.5 \times 22.5 \mathrm{~cm})$ and allowed to explore the chamber freely for $5 \mathrm{~min}$. The traveled distance and speed were recorded by the computer-based ANY-maze automated video-tracking system (Stoelting).

MWM test. Hippocampus-dependent spatial learning and memory were assessed using the acquisition phase of the standard MWM tests as described previously (Zhao et al., 2012). Starting on week 9 after injury,

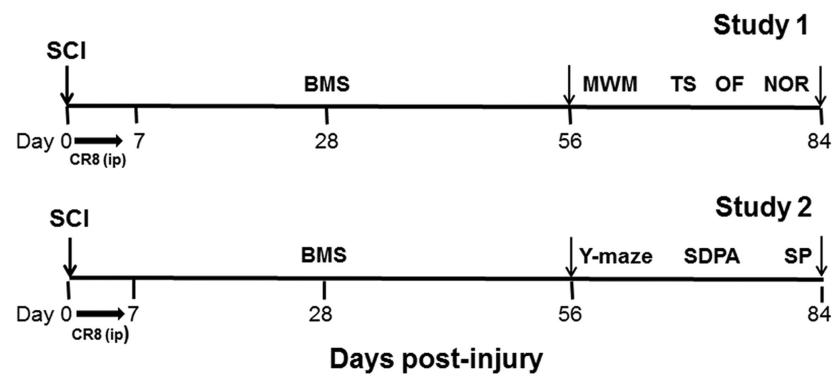

Figure 1. Timeline of the in vivo experimental design.

mice were trained to find the hidden submerged platform located in the northeast (NE) quadrant of the tank for 4 consecutive days with 4 trials per day. In all trials, mice were allowed to swim until they landed on the platform or $90 \mathrm{~s}$ had elapsed. The swim path, latency to platform, time spent in each zone, and velocity were recorded by the ANY-maze system. Reference memory was assessed by a probe test on day 5, during which the platform was removed. A visual cue test was subsequently performed using a flagged platform in NE quadrants (with a $90 \mathrm{~s} \mathrm{limit}$ per trial); latency (in seconds) to locate the flagged platform was recorded.

Water maze search strategy analysis was performed as described previously (Zhao et al., 2012). Three strategies were identified using the following categorization scheme: spatial strategies were defined as swimming directly to platform no more than one loop or swimming directly to the correct target quadrant and searching; systematic strategies were defined as searching interior portion of or entire tank without spatial bias and searching incorrect target quadrant; and looping strategies were defined as circular swimming around the tank, swimming in tight circle, and swimming around the wall of tank. The search strategies were analyzed on each of the 4 trials on training day 4 of MWM. The percentage of each strategy in each group was calculated.

$Y$-maze spontaneous alternation test. The Y-maze measures the willingness of rodents to explore new environments and assesses spatial working memory. Rodents typically prefer to investigate a new arm of the maze rather than returning to one that was visited previously. The Y-maze test was performed as described previously (Baratz et al., 2010; Sierksma et al., 2014) with some modifications. The Y-maze was built of black plastic and consisted of three identical arms. Each arm was 15 inches long $\times 2$ inches wide $\times 5$ inches high at an angle of $120^{\circ}$ with respect to the other arms. One arm was randomly selected as the "start" arm. The mouse was put into the end of the "start" arm and allowed to explore the maze freely for $10 \mathrm{~min}$. ANY-maze software records the trace of mouse for analysis. The arm entries (arms A-C) were recorded by analyzing the trace of mouse using ANY-maze software. It is considered an entry when all four paws of the mouse have entered the arm. An alternation is when the mouse enters three different arms consecutively. The percentage of alternation is calculated using the following equation: total alternations $\times$ $100 /$ (total arm entries -2 ). If a mouse scored significantly $>50 \%$ alternations (the chance level for choosing the unfamiliar arm), this was indicative of functional working memory.

NOR test. The NOR test was conducted on week 11 after injury, as described previously (Gresack et al., 2007; Zhao et al., 2012). Briefly, mice were habituated to the OF for $5 \mathrm{~min}$. After $24 \mathrm{~h}$, mice were placed into the chamber, where two identical objects were placed near the left and right corners of the OF for training (sample phase), and were allowed to explore freely until they spent a total of $30 \mathrm{~s}$ exploring the objects (exploration recorded when the front paws or nose contacted the object). Mice were then removed and returned to their home cages. After 24 h, object recognition was tested by substituting a novel object for a familiar training object (novel object location counterbalanced across mice). Time spent with each object was recorded. Because mice inherently prefer to explore novel objects, a preference for the novel object [more time than chance (15 s) spent with the novel object] indicates intact memory for the familiar object.

SDPA test. The SDPA test was performed as described previously (Huang et al., 2006) with some modifications. The mouse is placed on a 
plastic platform $(10 \times 5 \times 2.5 \mathrm{~cm}$ high $)$ positioned on a metal grid located inside one compartment $(24 \times 23 \times 27 \mathrm{~cm})$ of a PACS-30 passive avoidance apparatus (Columbus Instruments), with animals habituated to the compartment for $5 \mathrm{~min}$. Twenty-four hours later, the mouse is placed on the platform. When the mouse steps down onto the grid and has all 4 paws on it, it receives a $3 \mathrm{~s}, 0.3 \mathrm{~mA}$ foot shock and is immediately returned to the home cage. Twenty-four hours after conditioning, the mouse is returned to the platform and the latency to step down from the platform recorded (or when $5 \mathrm{~min}$ have elapsed). The mouse is not subjected to shock during testing.

TS test. The TS test assesses depression-like behavior in mice and is based on the observation that mice develop an immobile posture when placed in an inescapable hemodynamic stress of being hung by their tail (Steru et al., 1985; Cryan et al., 2005). The TS was performed on week 10 as described previously (Zhang et al., 2008) with small modifications. Each mouse was suspended at a height of $50 \mathrm{~cm}$ using adhesive tape placed $\sim 1 \mathrm{~cm}$ from the tip of its tail. The duration of immobility was recorded throughout the $5 \mathrm{~min}$ test period. The definition of immobility was passive hanging and complete motionlessness.

SP test. The SP test is used as an indicator of anhedonia, which is present in some affective disorders such as depression. In this test, we evaluate the mouse's interest in seeking a sweet rewarding drink relative to plain water. A diminished preference for the sweetened drink indicates depression-like behavior. The SP test was performed as described previously (Snyder et al., 2011; Hong et al., 2013) with some modifications. The hydrogel pack is weighted by subtraction of weight of empty insertion from an insertion with hydrogel pack and drink tip installed. The saccharine is weighed, dissolved in $5 \mathrm{ml}$ of plain water, and injected into hydrogel pack with a syringe to obtain a final $0.3 \%$ saccharine concentration. Initial weights of the hydrogel pack containing plain water and saccharine solution are recorded. Two inserts are placed in each cage, one with plain water in the normal (back) position and the saccharine water positioned at the front. Then, $100 \mathrm{~g}$ of food is added to each insert. The mouse is weighed and housed singly. After $24 \mathrm{~h}$, the water pouches, food, and mice are weighed and recorded. The insert with plain water and insert with saccharine water are rotated to avoid place preference. After a second $24 \mathrm{~h}$ period, the water pouches, food, and mice are again weighed and recorded. The SP is calculated by divided consumption of sweetened water by total consumption of water (sweetened water plus plain water). The food preference is also calculated as a control to demonstrate that mice do not show a place preference.

$q R T-P C R$ analysis. Total RNA was isolated by using a miRNeasy isolation kit (QIAGEN) with on-column DNase treatment (QIAGEN). The Verso cDNA Kit (Thermo Scientific) was used to synthesize cDNA from purified total RNA. RNA $(1 \mu \mathrm{g})$ was heated to $70^{\circ} \mathrm{C}$ for $5 \mathrm{~min}$ and mixed with $5 \times$ cDNA-synthesis buffer, dNTP mix ( $0.5 \mathrm{~nm}$ final concentration), and Verso Enzyme Mix, and random hexamers $(400 \mathrm{ng} / \mu \mathrm{l})$ were added. Tubes were incubated at $42^{\circ} \mathrm{C}$ for $30 \mathrm{~min}$, followed by $95^{\circ} \mathrm{C}$ for $2 \mathrm{~min}$. qRT-PCR amplification was performed by using cDNA TaqMan Universal Master Mix II (Applied Biosystems). In brief, reactions were performed in duplicate containing $2 \times$ TaqMan Universal Master Mix II, 1 $\mu \mathrm{l}$ of cDNA (corresponding to $50 \mathrm{ng}$ of RNA/reaction), and the TaqMan Gene Expression Assay (Applied Biosystems) at $20 \times$ in a final volume of $20 \mu$ l. Real-time PCR was performed using cDNA TaqMan Universal Master Mix II (Applied Biosystems) on an ABI 7900 HT FAST Real Time PCR (Applied Biosystems). The PCR profile consisted of 1 cycle at $50^{\circ} \mathrm{C}$ for $2 \mathrm{~min}$ and $95^{\circ} \mathrm{C}$ for $10 \mathrm{~min}$, followed by 40 cycles at $95^{\circ} \mathrm{C}$ for $15 \mathrm{~s}$ and $60^{\circ} \mathrm{C}$ for $1 \mathrm{~min}$. Gene expression assays for the following genes were used: TNF $\alpha$ (Mm00443258_m1), inducible nitric oxide synthase (iNOS; Mm00440502_m1), CD86 (Mm00444543_m1), CCL2 (Mm00441242_ m1), CCL3 (Mm00441259_g1), IL-6 (Mm00446190_m1), IL-10 (Mm00439614_m1), Arg-1 (Mm00475988_m1), Ym1 (Mm00657889_mH), IL-4R $\alpha$ (Mm01275139_m1),SOCS3(Mm00545913_s1), TGF $\beta(M m 011-$ 78820_m1), synapsin 1 (Mm00446190_m1), CREB (Mm00501607_ m1), BDNF (Mm01334042_m1), IGF-1 (Mm00439560_m1), cyclin A1 (Mm00432337_m1), cyclin A2 (Mm00438063_m1), cyclin B1 (Mm03053893_gH), cyclin D1 (Mm00432359_m1), E2F1 (Mm00432936_m1), PCNA (Mm00448100_g1). Gene expression was normalized to GAPDH (Mm99999915_g1) and the relative quantity of mRNAs was calculated based on the comparative Ct method (Livak and Schmittgen, 2001; Sabirzhanov et al., 2012).

Unbiased stereological quantification of microglial phenotypes. At specific times after injury, mice were deeply anesthetized with sodium pentobarbital (100 mg/kg, i.p.) and transcardially perfused with $100 \mathrm{ml}$ of normal saline followed by $200 \mathrm{ml}$ of PBS containing 4\% PFA, pH 7.4. The brain were removed, postfixed in $4 \%$ PFA overnight, and transferred to $30 \%$ sucrose at $4^{\circ} \mathrm{C}$. Coronal sections were cut with a cryostat, thawmounted onto Superfrost Plus slides, and stained for anti-ionized calcium-binding adaptor molecule 1 (Iba-1, 1:1000; Wako Chemicals) antibody and DAB. The number of the three microglial morphological phenotypes (ramified, hypertrophic, and bushy) was quantified using the optical fractionator method of unbiased stereology (West et al., 1991) with StereoInvestigator Software (MBF Biosciences). The sampled region was the subregions of hippocampus and cerebral cortex between -1.22 and $-2.54 \mathrm{~mm}$ from bregma. Every fourth $60 \mu \mathrm{m}$ section was analyzed beginning from a random start point. The optical dissector had a size of $50 \times 50 \mu \mathrm{m}$ in the $x$-axis and $y$-axis with a height of $10 \mu \mathrm{m}$ and guard zone of $4 \mu \mathrm{m}$ from the top of the section. Dissectors were positioned every $150 \mu \mathrm{m}$ in the $x$-axis and $y$-axis. Microglial phenotypic classification was based on the length and thickness of the projections, the number of branches, and the size of the cell body, as described previously (Soltys et al., 2001; Byrnes et al., 2012). The volume of the region of interest was measured using a Cavalieri estimator method with a grid spacing of $100 \mu \mathrm{m}$. The estimated number of microglia in each phenotypic class was divided by the volume of the region of interest to obtain the cellular density expressed in cells $/ \mathrm{mm}^{3}$. Neurolucida software (MBF Biosciences) was used to create reconstructions of microglia at different stages of activation after injury by tracing the cell bodies and dendrites (Wu et al., 2013b).

Stereological assessment neuronal survival in hippocampal subregions. Total number of surviving neurons in the CA1, CA2 $/ 3$, and dentate gyrus (DG) subregions of the hippocampus were counted using the optical fractionator method of unbiased stereology. Briefly, the optical dissector had a size of $50 \times 50 \mu \mathrm{m}$ in the $x$-axis and $y$-axis with a height of $10 \mu \mathrm{m}$ and guard zone of $4 \mu \mathrm{m}$ from the top of the section. Dissectors were positioned every $150 \mu \mathrm{m}$ in the $x$-axis and $y$-axis. The sampled region for each hippocampal subfield was demarcated and cresyl violet neuronal cell bodies were counted. The volume of the hippocampal subfield was measured using the Cavalieri estimator method. The estimated number of surviving neurons in each field was divided by the volume of the region of interest to obtain the cellular density expressed in cells per cubic micrometer.

Immunofluorescent staining. Standard fluorescent immunocytochemistry was performed on $20-\mu \mathrm{m}$-thick sections as described previously (Wu et al., 2013a). The primary antibodies rabbit anti-Iba-1 (1:1000), rabbit anti-major histocompatibility complex class II (MHC II, clone CR3/43, 1:500; Dako), goat anti-doublecortin (1:200; Santa Cruz Biotechnology), and mouse anti-cyclin D1 (1:500; Neomarker) were used, along with standard immunostaining techniques. Counterstaining was performed with DAPI ( $1 \mu \mathrm{g} / \mathrm{ml}$; Sigma). For MHC II staining, sections were incubated with biotinylated anti-rabbit IgG antibody (Vector Laboratories) for $2 \mathrm{~h}$ at room temperature, and then incubated in avidin-biotin-horseradish peroxidase solution (Vectastain elite $\mathrm{ABC}$ kit; Vector Laboratories) for $1 \mathrm{~h}$ and then reacted with 3,3diaminobenzidine (Vector Laboratories) for color development. All immunohistological staining experiments were performed with appropriate positive control tissue and primary/secondary-only negative controls. Fluorescence microscopy was performed using an TCS SP5 II confocal microscope system (Leica). The images were processed using Adobe Photoshop Version 7.0 software. For quantitative image analysis, digital images at $63 \times$ magnification were captured from the hippocampus (for MHC II expression) or DG subregion (for doublecortin-positive cells) based on atlas boundaries and using a confocal laser-scanning microscope ( $n=5$ images/location/mouse for 5-6 mice/group). These were analyzed to quantify MHC II immunointensity or doublecortinexpressing cells with ImageJ software version 1.43. Based on the gray values of digital images, the threshold was set to display only fluorescence-positive pixels (Lee et al., 2013; Wu et al., 2013b). 
Western blots. Hippocampus and cerebral cortical tissue were collected and used for Western blotting analysis as described previously (Wu et al., 2013a). Briefly, the tissue was homogenized and sonicated in radioimmunoprecipitation assay buffer (Sigma) and then centrifuged at $20,600 \times g$ for $20 \mathrm{~min}$ at $4^{\circ} \mathrm{C}$. The supernatant was removed and protein concentration was determined using the Pierce BCA Protein Assay kit with a bovine serum albumin standard. Each sample contained proteins from one animal. Equal amounts of protein were electrophoretically separated on $4-12 \%$ NuPAGE Novex Bis-Tris gradient gels (Invitrogen) and transferred to nitrocellulose membranes (Invitrogen). The blot was then probed with the following antibodies: rabbit anti-Iba-1 (1:1000); rabbit anti-CDK4 (1:1000; Santa Cruz Biotechnology), and mouse anticyclin D1 (1:500). The immunoreactivity was detected using SuperSignal West Dura Extended Duration Substrate (Thermo Scientific). Chemiluminescence was captured on a Kodak Image Station 4000R station and protein bands were quantified by band densitometry using the Gel-Pro Analyzer program (Media Cybernetics). The loading and blotting of equal amounts of protein were verified by reprobing the membrane with mouse antiGAPDH (1:1000; Millipore).

Statistical analysis. Unless indicated otherwise, results are expressed as mean \pm SEM, where " $n$ " is the number of individual animals. Behavior and unbiased stereological analysis were performed by the investigators blinded to groups. Statistical comparisons included twoway ANOVA with repeated measures in behavioral experiments and $\chi^{2}$ analysis for search strategy analysis. For multiple comparisons, one-way ANOVA followed by Student's Newman-Keuls post hoc test. All statistical analyses were conducted with Prism version 3.02 for Windows (GraphPad Software) or SigmaPlot version 12 (Systat Software). For nonparametric data, the Wilcoxon's exact test was used. SAS version 9.3 was used for this test. Statistical significance was set at $p \leq$ 0.05 .

\section{Results}

Cognitive function is impaired in mice after contusive SCI To investigate whether SCI mice have cognitive impairments, we first performed the MWM test, which measures hippocampusdependent spatial learning and memory at 9 weeks after injury. Initial pilot studies demonstrated that the protocol used for the MWM test is feasible in experimental SCI, indicating that, notwithstanding the motor deficits, injured mice retain swimming capability. We observed that SCI mice frequently used their forelimbs and body to swim because their hindlimb function was impaired. In the acquisition phase of MWM test (Fig. 2A), a significant difference was detected between the Sham/Vehicle and SCI/Vehicle groups at training day $4(p<0.001)$. Because our prior work implicated a role for CCA in chronic motor deficits after SCI and cognitive dysfunctions after TBI, as well as injured-induced microglial activation, we here also evaluated CCA pathways through administration of CDK inhibitor after SCI. There were no significant differences between the Sham/ Vehicle and Sham/CR8 groups or the SCI/Vehicle and SCI/CR8
B

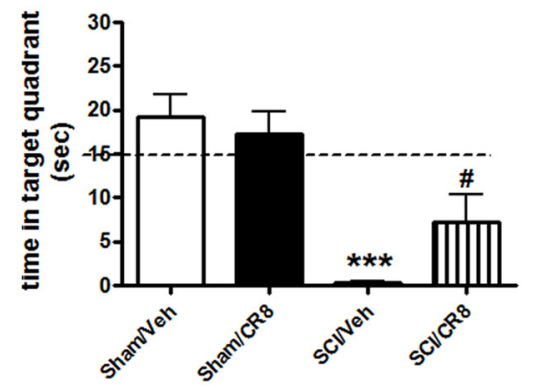

Sham

D

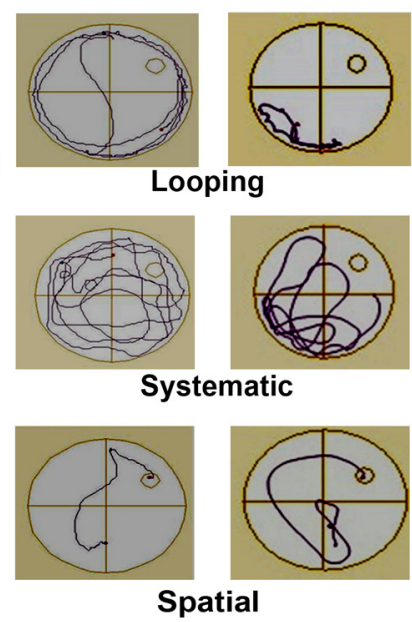

Spatial

Figure 2. Effects of contusion SCl in mice on hippocampus-dependent spatial learning and memory tested in MWM. A, Acquisition trials. A significant difference was detected between the Sham/Vehicle $(n=14)$ and SCI/Vehicle $(n=15)$ groups at training day $\left.4{ }^{* * *} p<0.001\right)$. No differences were found between the Sham/Vehicle $(n=14)$ and Sham/CR8 $(n=15)$ groups or the e is predominant in the SCI/Vehicle group (63.2\%) compared with the Sham/Vehicle group (7.4\%), whereas SCI mice with CR8 treatment displayed increased spatial type (8.8\% vs $4.4 \%$ from SCI/Vehicle mice) and reduced looping type $\left(38.2 \% ; \chi^{2}=63.03\right.$, $p<0.001)$. D, Representative types of search strategies. SCI mice showed less traveled distance than uninjured Sham mice.

groups across each of the training days. On training day 5, the probe test, in which the time spent in the target quadrant was calculated, was performed (Fig. 2B). SCI/Vehicle mice spent significantly less time in the target quadrant compared with Sham/ Vehicle mice $(p<0.001)$. Notably, a significant difference was also observed between the SCI/Vehicle and SCI/CR8 groups $(p<$ $0.05)$. No differences were observed between the two Sham groups. Swim speed analyses showed that there were significant reductions in swim speed in the SCI/Vehicle group (0.025 \pm $0.005 \mathrm{~m} / \mathrm{s}, p<0.001)$ compared with the Sham/Vehicle group $(0.062 \pm 0.009 \mathrm{~m} / \mathrm{s})$. CR8 did not improve the swim speed of injured mice $(0.025 \pm 0.005 \mathrm{~m} / \mathrm{s})$. In addition, visible cue tests were performed on training day 5. Not surprisingly, SCI/Vehicle mice $(78.83 \pm 5.15 \mathrm{~s}, p<0.001)$ revealed a significant increase in latency time to locate the visible platform compared with the Sham/Vehicle mice $(41.03 \pm 8.41 \mathrm{~s})$.

We then performed search strategy analysis to evaluate the efficiency of locating the platform, an outcome that is less influenced by locomotion deficits. Based on previously published criteria (Zhao et al., 2012), 3 search strategies were evaluated for each of the 4 trials on training day 4 . Occasionally, mice changed search strategies during a trial. When this happened, the strategy 

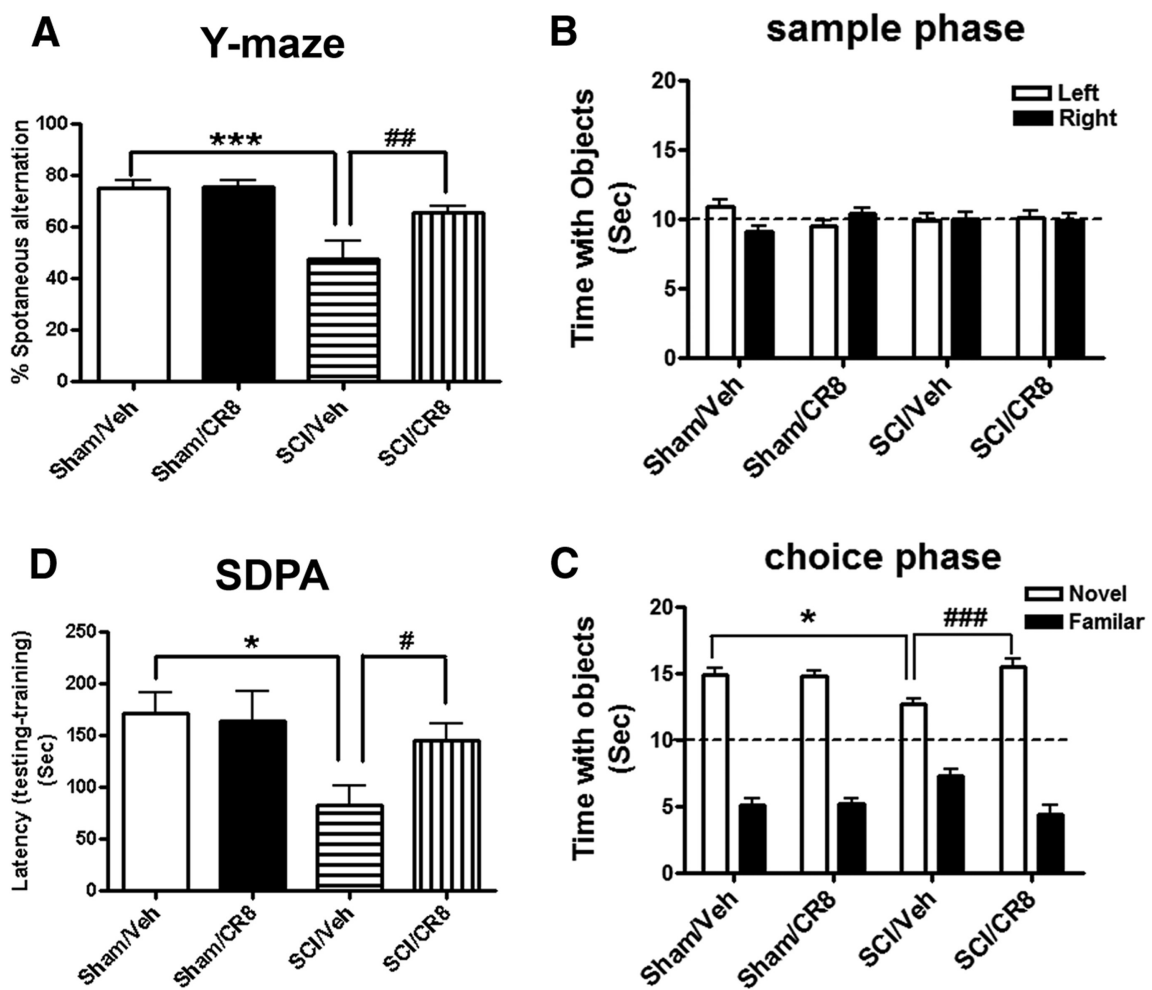

Figure 3. Assessment of spatial, emotional, or nonspatial memory using the Y-maze spontaneous alteration $(\boldsymbol{A}), \operatorname{NOR}(\boldsymbol{B}, \boldsymbol{C})$, and SDPA $(\boldsymbol{D})$ tests. $\boldsymbol{A}$, Sham mice showed intact spatial working memory function because they all performed significantly better than the $50 \%$ chance level $(n=10)$. SCI mice $\left(n=14,{ }^{* * *} p<0.001\right)$ showed significantly reduced percentages of spontaneous alteration in Y-maze test, whereas CR8-treated mice $(n=14$, \#\#\#p < 0.01) had a significantly increased percentage of spontaneous alteration compared with $\mathrm{SCl} /$ Vehicle mice at 9 weeks after injury. $\boldsymbol{B}$, Injured or uninjured mice spent equal time with the two identical objects during the sample phase. C, SCI/Vehicle mice $(n=17)$ spent significantly less time with the novel object than mice in the Sham/Vehicle group $\left(n=10,{ }^{*} p<0.05\right)$ and the SCI/CR8 group ( $n=14$,\#\#\#p<0.001). $\boldsymbol{D}$, During testing for their memory of the aversive experiences $24 \mathrm{~h}$ later, $\mathrm{SCI}$ mice $\left(n=14,{ }^{*} p<0.05\right)$ showed significant reduced latency to step down from the platform compared with Sham mice $(n=10)$. CR8 treatment $\left(n=14,{ }^{\#} p<0.05\right)$ caused a significant increased latency compared with SCI/Vehicle mice.

that best described the major swimming path was assigned. Search strategy in the MWM showed good group separation $\left(\chi^{2}=63.02, p<0.001\right.$; Fig. $\left.2 C\right)$. SCI mice exhibited significantly higher reliance on looping search strategies than spatial and systematic search strategies compared with Sham mice. Specifically, the use of spatial search strategies ranged from $25.0 \%$ in the Sham/Vehicle group to $4.4 \%$ in the SCI/Vehicle group. CR8 increased the use of this type of swim path to $8.8 \%$. Figure $2 D$ shows different representative search strategy pathways between Sham and SCI mice.

To assess spatial working memory and to minimize the potentially confounding factor of altered motor activity, the Y-maze spontaneous alternation test was also performed. Sham mice showed $\sim 75 \%$ spontaneous alteration, indicative of functional working memory. Moderate SCI caused a significant reduction of spontaneous alteration compared with Sham animals $(p<0.001$; Fig. $3 A$ ). SCI mice treated with CR8 showed significantly increased spontaneous alteration compared with SCI/Vehicle mice at 9 weeks after injury $(p<0.01)$. Next, retention memory was assessed by the NOR test, which is less dependent on locomotion. As shown in Figure 3B, mice from both Sham groups spent more time than chance ( $15 \mathrm{~s}$ ) with the novel object $1 \mathrm{~h}$ after training (sample phase), indicating intact memory. SCI/Vehicle mice spent less time with the novel object ( $p<0.05$ vs Sham/Vehicle group), but significantly greater time than chance (Fig. $3 C$ ). No- tably, CR8 treatment in SCI mice reversed these reduced time periods with the novel object ( $p<0.001$ vs SCI/Vehicle group). To reduce the potential confounding effects of motor deficits and to further confirm that SCI mice have cognitive impairments and cell cycle inhibitor improvement of memory performance, we also used other, more complex behavioral training paradigms that include spatial and emotional motivations such as step-down fear avoidance. This is a fear-motivated learning task that is not dependent on motor function. During step-down fearconditioning trials, all groups exhibited similar short retention times before stepping down onto the platform and receiving a shock. During testing for memory of the aversive experiences $24 \mathrm{~h}$ later, SCI mice showed significantly reduced latency to step down from the platform compared with Sham mice ( $p<0.01$; Fig. $3 D)$. Notably, the CR8-treated SCI mice showed significantly greater latencies than vehicletreated SCI animals.

We also investigated the long-term effects of SCI on depression-like behavior. A TS test was performed at 10 weeks after injury. Sham mice revealed an immobility time of $\sim 80$ s (Fig. $4 A$ ). No differences were observed between the two Sham groups. However, SCI resulted in significantly increases in immobility times compared with Sham/Vehicle group $(p<$ $0.05)$. Treatment with CR8 showed significantly reduced immobility times $(p<$ 0.01 vs SCI/Vehicle group) to levels similar to Sham mice. To reduce the potential confounding effects of motor deficits, water/food motivations were also evaluated in SCI mice using the SP test. SCI mice showed significantly reduced sweet water consumption without a change in food consumption, indicating depression-like behavior (Fig. $4 B-F$ ). CR8 treatment significantly increased sweet water consumption, but did not alter consumption of plain drinking water or food.

Collectively, these data show that SCI mice performed poorly in the MWM, Y-maze, NOR, and SDPA tests, indicating impaired spatial and nonspatial learning and memory, and exhibit depressionlike behavior; such changes were limited by cell cycle inhibition.

\section{Motor function is deficit after SCI}

The OF test was performed at 10 weeks after SCI to examine spontaneous locomotor activity (Fig. $5 A, B$ ). Mice from both Sham groups displayed similar locomotor activity (distance traveled and walking speed) during the 5 min of testing. SCI mice showed significantly reduced traveled distance $(1.94 \pm 0.15 \mathrm{~m}$, $p<0.001)$ compared with Sham/Vehicle mice $(3.21 \pm 0.34 \mathrm{~m})$. Decreased traveled distance in SCI mice was paralleled by reduced walking speed. We did not observe any improvement of spontaneous locomotor activity in SCI/CR8 group, which is consistent with the results of swim speed in the MWM test.

Hindlimb functions were also evaluated in these mice in the OF test on day 1 after injury and weekly thereafter for up to 8 
A

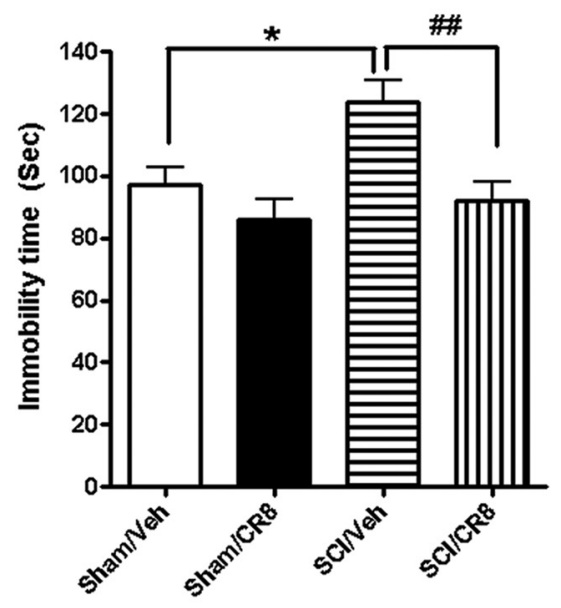

D

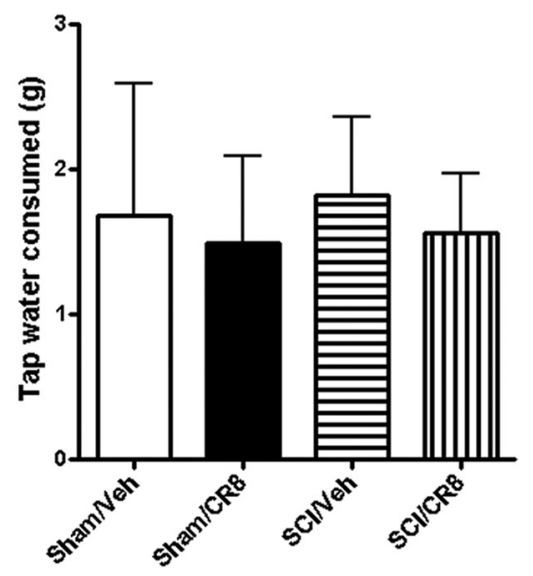

B

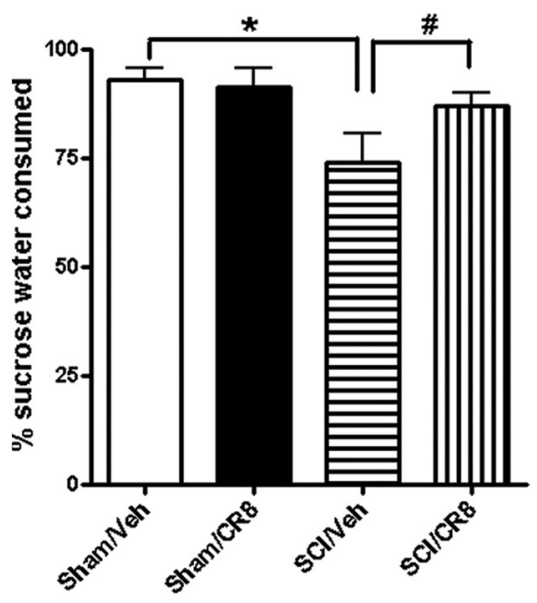

E

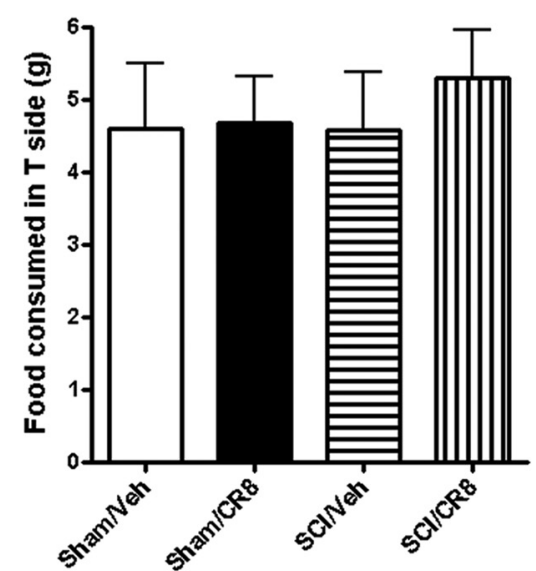

C

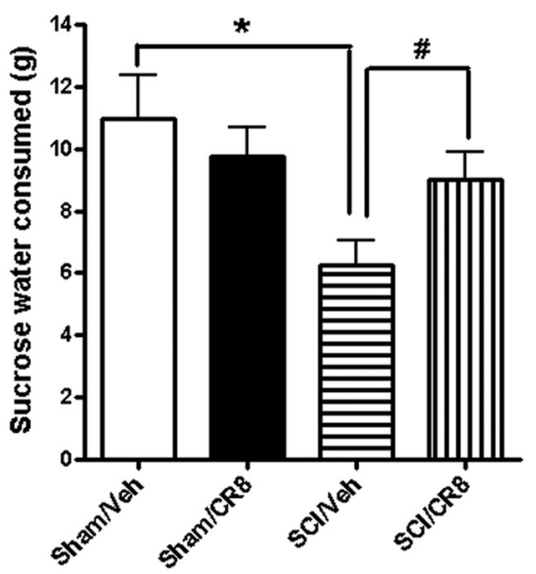

F

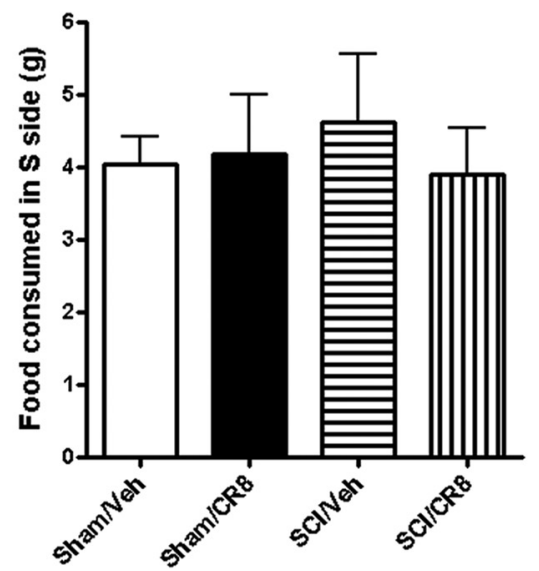

Figure 4. Assessment of depression-like behaviors using the TS and SP tests. $\boldsymbol{A}$, Sham/Vehicle mice showed an immobility time of $97.3 \pm 5.6 \mathrm{~s}$, whereas no differences were found between the Sham/Vehicle $(n=10)$ and Sham/CR8 $(n=10)$ groups. However, significantly increased immobility times were observed in SCI/Vehicle group $\left(n=17,{ }^{*} p<0.05\right)$. CR8 treatment $(n=17)$ reversed immobility times compared with the SCI/Vehicle group (\#\#p $<0.01)$. $\boldsymbol{B}, \boldsymbol{C}$, Both Sham groups similarly preferred sucrose. SCI mice $(n=14)$ showed significantly reduced percentages $(\boldsymbol{B})$ or absolute grams $(\boldsymbol{C})$ of sucrose water consumed compared with Sham mice $\left(n=10,{ }^{*} p<0.05\right)$. However, significantly increased SP was observed in CR8-treated mice $(n=14$, \#p $<0.01)$. $\boldsymbol{D}$, SCl or CR8 treatment did not alter plain drinking water consumed. $\boldsymbol{E}, \boldsymbol{F}$, Neither SCI nor CR8 changed food consumed in tap water (T) or sucrose water (S) sides.

weeks using the BMS scores (Basso et al., 2006). One day after SCI, all mice had a BMS score of 0 or 1 , indicating nearly complete loss of motor function (Fig. 5C). Three hours after injury and once daily for 6 consecutive days after the injury, the mice systemically received intraperitoneal injections of CR8 $(1 \mathrm{mg} / \mathrm{kg})$ or saline. CR8-treated SCI mice $(n=17)$ had significantly better BMS scores than the saline-treated SCI mice $(n=17 ; p<0.05)$ by day 14 , and this effect persisted through day 56 after SCI, consistent with our prior study in the SCI mice with intrathecal administration of CR8 (Wu et al., 2013a). Therefore, inhibiting cell cycle activation improves the recovery of hindlimb function, but not spontaneous locomotor activity, in SCI mice.

\section{SCI alters M1 (classical) and M2 (alternative) microglia} activation genes in the hippocampus

To begin assessing the molecular basis for SCI-induced cognitive decline and depressive-like behavior, we collected hippocampus tissues from Sham or SCI mice at $1 \mathrm{~d}, 8 \mathrm{~d}$, and 12 weeks after injury because this brain region is most likely to be responsible for the behavior abnormalities observed in the present study. We started by examining the effects of SCI on microglia activation, which is known to be associated with poorer neurological recovery and increased neurodegeneration (Kumar and Loane, 2012). We measured the expression of microglia genes associated with classical (M1), alternative activation (M2a), and acquired deactivation (M2c), based on identifying antigenic markers for each microglia state (Colton, 2009). Figure 6A showed the relative microglia mRNA expression of M1 genes: TNF $\alpha$, iNOS, CD86, chemokine (C-C motif) ligand 2 (CCL2), chemokine (C-C motif) ligand 3 (CCL3), and IL6. SCI significantly increased the mRNA levels of these M1 type genes in the hippocampus compared with Sham-injured controls, most of them upregulated at later time points after injury (Fig. 6A). SCI-induced CCL2 expression was increased as early as at $24 \mathrm{~h}$ after injury. IL6 mRNA levels were significantly increased at $8 \mathrm{~d}$ after injury and further increased at 12 weeks. Notably, these elevations were significantly suppressed by CR 8 treatment.

The M2a genes arginase-1 (Arg-1) and Ym1 and the M2c genes IL-4 receptor- $\alpha$ (IL-4R $\alpha$ ), suppressor of cytokine signaling 3 (SOCS3), and transforming growth factor- $\beta$ (TGF $\beta$ ) were se- 

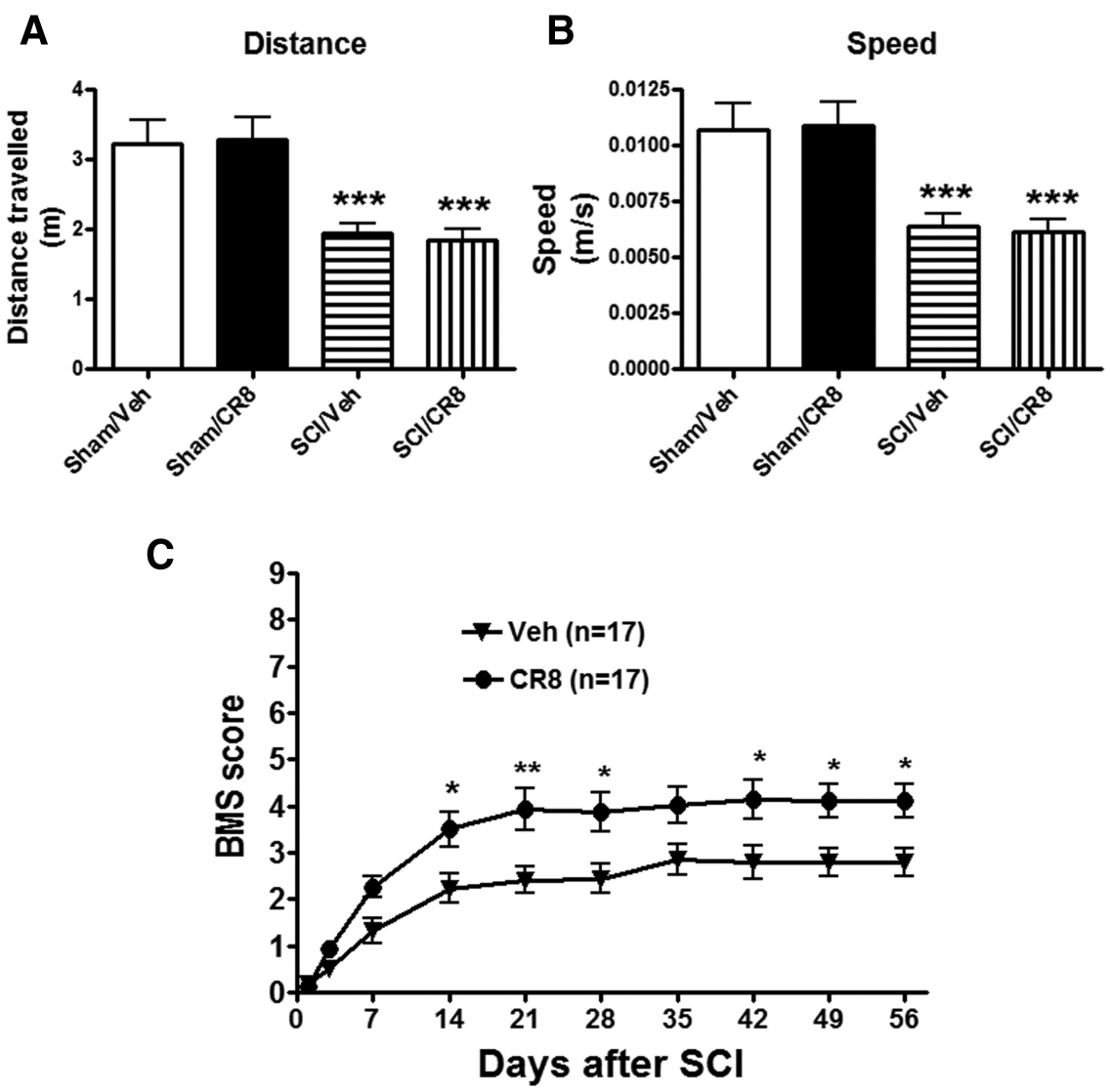

Figure 5. Determination of spontaneous locomotor activity and hindlimbs functions using the $\mathrm{OF}$ test. $\boldsymbol{A}, \boldsymbol{B}$, Traveled distance and speed. SCI resulted in a significant reduced distance traveled $\left(n=17,{ }^{* * *} p<0.001\right)$ and walking speed $\left({ }^{* * *} p<0.001\right)$ compared with Sham/Vehicle mice $(n=10)$. CR8 treatment $(n=15)$ did not improve spontaneous locomotor activity. C, Hindlimb locomotor function was evaluated using the BMS score. Significantly improved functional recovery in CR8-treated mice $(n=17)$ was observed compared with saline-treated mice $(n=17) .{ }^{*} p<0.05,{ }^{* *} p<0.01$ compared with the saline-treated group.

lected in the present study (Fig. $6 B, C$ ) because they have been shown to be robustly increased in the brain after TBI. Interestingly, we did not observe any significant changes in the levels of these genes in the hippocampus after SCI. In contrast, the antiinflammatory cytokine IL10 was found to be significantly increased at 12 weeks after injury compared with Sham/Vehicle controls $(p<0.001 ;$ Fig. $6 D)$. These results indicate that lesion to the spinal cord alters the balance of M1 and M2 microglia expression patterns in the brain, with significantly increased expression of M1, without disturbing several key M2 genes.

It is well known that the expression of MHC II (an M1 marker) is a hallmark of antigen-presenting cells, and its expression on activated microglia/macrophage enables their interaction and signaling with other cells such as T cells (Sedgwick et al., 1998). We have shown previously that MHC II is highly expressed in the aged traumatically injured brain by microglial/macrophage that displayed a highly activated cell morphology (Kumar et al., 2013). In the present study, we evaluated MHC II expression in the hippocampus at 12 weeks after SCI using the HLA-DP, DQ, DR antigen (CR3/43 clone) antibody, which has been used to detect chronically activated microglia in postmortem human TBI brain (Johnson et al., 2013). MHC II immunoreactivity was not detectable in the Sham brain, but was increased in cells that displayed activated microglia/macrophage cellular morphology in the hippocampus of the SCI brain. Quantification analyses showed a significant increase of MHC II expression in the hip- pocampus from SCI mice compared with Sham mice ( $p<0.001$; Fig. $6 E)$. CR8 treatment significantly reduced SCI-induced upregulation of MHC II expression. Figure 6, $F$ and $G$, show representative immunohistochemical (IHC) images. IHC using antibodies against M2 markers (arginase-1, YM1, TGF- $\beta$ ) showed no detectable immunoactivity in either Sham or SCI brain (data not shown).

\section{Highly reactive microglial activation phenotypes predominate chronically in the brain after SCI}

When microglia become activated, their morphologies switch from a resting status displaying ramified cellular morphologies to activated forms displaying cellular hypertrophic or bushy morphologies. We performed unbiased stereological assessment to examine microglial cell numbers and activated forms in the hippocampus and cerebral cortex after SCI. Representative images and reconstructions (Neurolucida) of the resting (ramified, small cell body with elongated and thin projections) and activated (hypertrophic, large cell body with shorter and thicker projections; bushy, enlarged cell body with multiple short processes that form thick bundles) microglia were presented (Fig. 7A). At $8 \mathrm{~d}$ after SCI, no significant differences were observed in the number of ramified, activated, and total microglia across the groups (Fig. $7 B, C$ ). However, 12 weeks after SCI, there were significantly increased numbers of microglia displaying the highly activated (hypertrophic and bushy) phenotype and reduced ramified phenotypes in both hippocampus and cerebral cortex of SCI mice compared with Sham mice (Fig. 8). Notably, CR8 treatment significantly reversed these changes. We did not observe any significant differences in the number of total Iba- $1^{+}$ microglia across the groups.

Immunofluorescence also confirmed microglia morphological changes in the brain after SCI (Fig. 9A). Western blot analysis of Iba- 1 protein expression at 12 weeks after injury indicated a significant increase in expression in both hippocampus and cerebral cortex of SCI mice compared with Sham tissue (Fig. 9B,C). However, CR8 significantly attenuated the Iba- 1 protein expression in the both brain regions compared with the SCI group.

Together, these data suggest that microglia activation was upregulated chronically in the brain after SCI and was suppressed by cell cycle inhibition.

\section{SCI mediates chronic hippocampal neurodegeneration}

Given that microglia activation is upregulated in the brain after SCI and that SCI mice display learning and memory impairments, we investigated whether there is a neurodegeneration in key brain regions after injury. Unbiased stereological techniques were used to quantify surviving neurons in the CA1, CA2/3, and DG subregions of the hippocampus in cresyl-violet-stained brain sections from Sham or SCI mice at $8 \mathrm{~d}$ or 12 weeks after injury. At $8 \mathrm{~d}$ after SCI, no differences were observed in the number of 



\section{Anti-inflammatory cytokine}

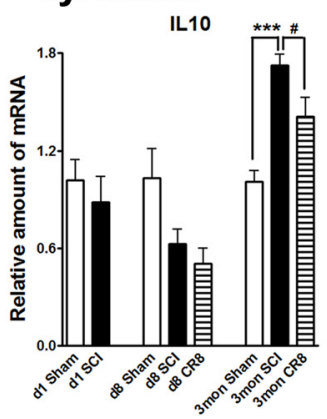

iNos

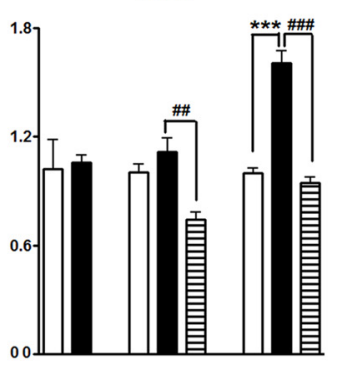

CCL2

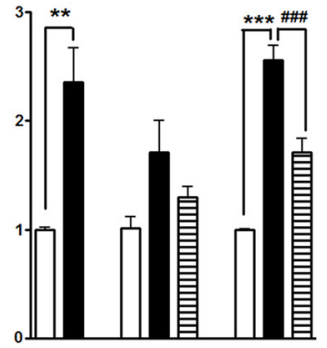

IL6

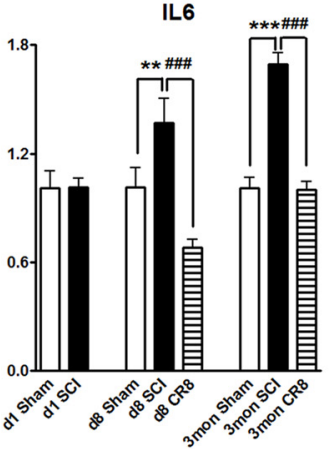

E



B Alternative activation (M2a)

Arg-1

Ym1

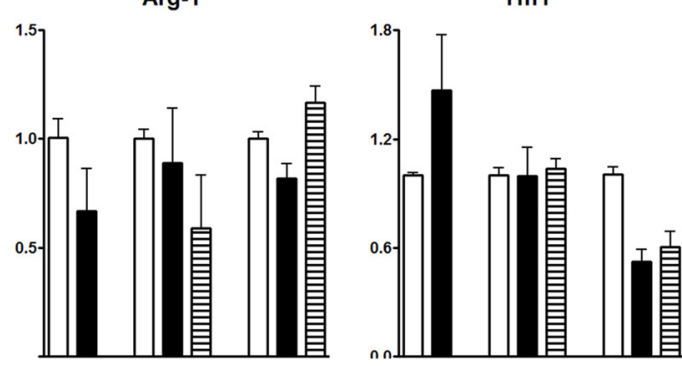

C Acquired deactivation (M2c)
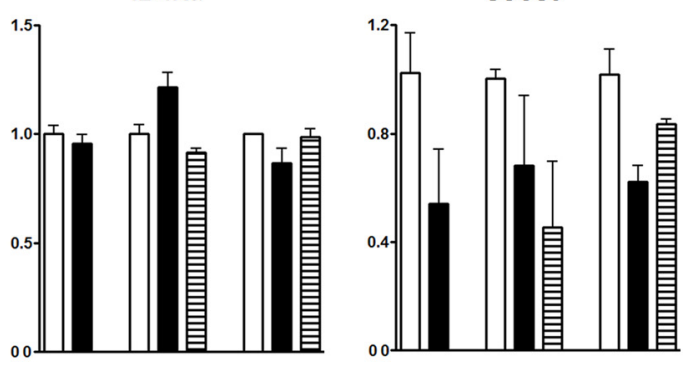

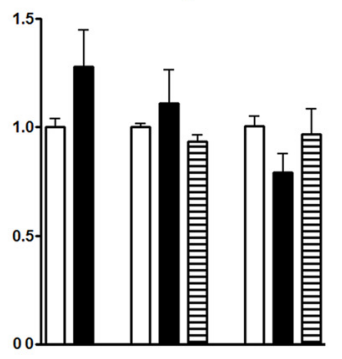

\section{$\mathbf{F}$}

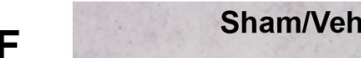

Sham/CR8

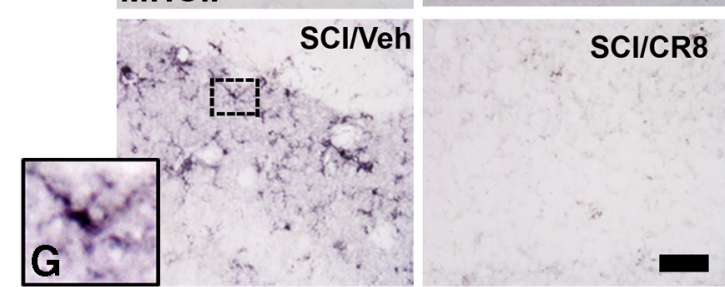

Figure 6. SCl alters expression of $\mathrm{M} 1$ (classical)/M2 (alternative) microglia genes as well as MHC II immunoreactivity in the hippocampus. qRT-PCR analysis was performed at $1 \mathrm{~d}, 8 \mathrm{~d}$, or 12 weeks after injury. $A, \mathrm{M} 1$ gene expression levels (TNF $\alpha, \mathrm{NNOS}, \mathrm{CD} 86, \mathrm{CCL}$, CCL3, IL6) were progressively increased in SCI/Vehicle mice compared with the Sham groups and were reduced by CR8 treatment. $\boldsymbol{B}, \boldsymbol{C}$, Moderate SCI did not alter expression levels of the M2a genes (Arg-1, Ym1) or the M2c genes (IL-4R $\alpha$, SOCS3, TGF $\beta$ ) in the hippocampus at all time points. $D$, The anti-inflammatory cytokine IL10 was significantly increased at 12 weeks after injury compared with Sham mice and lower in CR8-treated mice. ${ }^{* *} p<0.01,{ }^{* * *} p<0.001$ versus Sham groups; \#\#p $<0.01$, \#\#\#p<0.001 versus SCl groups. $n=3$ (d1 Sham), $n=5$ (d1 SCl), $n=3$ (d8 Sham), $n=5$ (d8SCl), $n=5$ (d8 CR8), $n=5$ (3mon Sham), $n=9$ (3mon SCl), and $n=7$ (3mon CR8). E, Quantification of immunoreactivity for $\mathrm{MHC}$ II revealed significant increased expression in the hippocampus at 12 weeks after $\mathrm{SCl}$ compared with the Sham group. These changes were remarkably suppressed by $\mathrm{CR} 8$ treatment. $n=$ 5 images/location/mouse for $5-6$ mice/group. . $p<0.05$ versus Sham/Vehicle group; \#p $<0.05$ versus $S C I / V e h i c l e ~ g r o u p . ~ F, G$, Representative images showed that MHC II immunoreactivity was not detectable in the Sham brain, but increased in cells that displayed activated microglia/macrophage cellular morphology ( $G$, insert) in the hippocampus of the SCI brain. Scale bar, $25 \mu \mathrm{m}$.

neurons across the groups (Fig. 10A). However, at 12 weeks after injury, SCI resulted in significant neuronal cell loss in the hippocampus ( $p<0.05$ vs Sham/Vehicle group; Fig. 10B). Systemic administration of CR8 significantly improved neuronal survival compared with SCI/Vehicle samples $(p<0.01)$. Therefore, these data demonstrate that SCI leads to chronic neurodegeneration in the hippocampus and that CR8 provides neuroprotection.

To determine the impact of SCI on adult neurogenesis, we performed IHC staining for doublecortin to label immature neurons in the DG of the hippocampus, a good indicator of neuro- 
A

Ramified

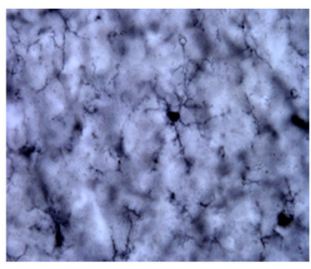

Hypertrophic



Bushy

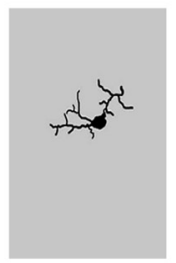

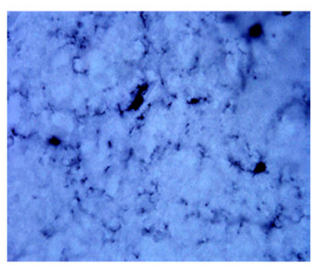

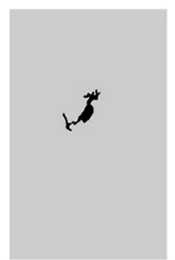

\section{B Hippocampus}


\section{c Cerebral cortex}
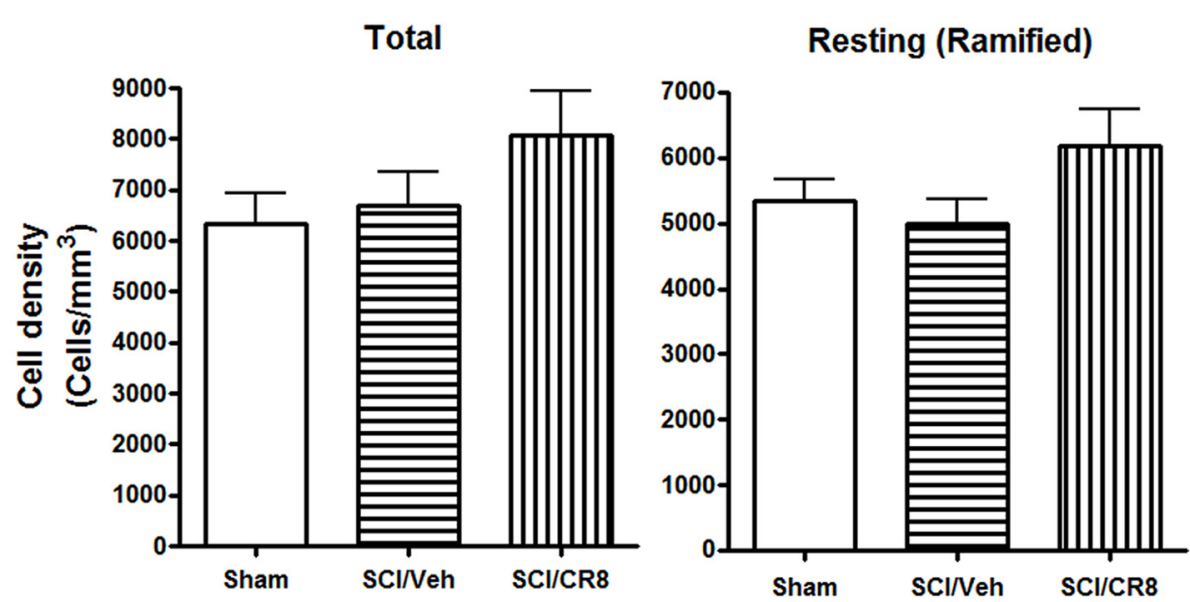

Activated

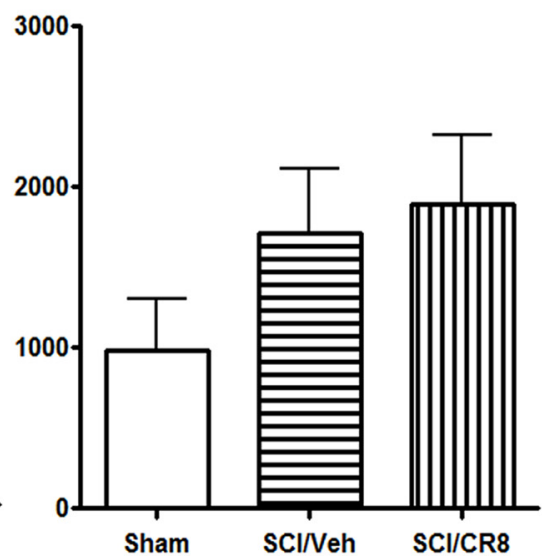

Figure 7. SCI did not change microglial phenotypes in the hippocampus and cerebral cortex at $8 \mathrm{~d}$ after injury. $\boldsymbol{A}$, Representative lba-1 IHC images displaying resting (ramified morphology) or activated (hypertrophic or bushy morphology) microglial phenotypes and the corresponding Neurolucida reconstructions. $\boldsymbol{B}, \mathbf{C}$, Unbiased stereological quantitative assessment in the hippocampus $(B)$ and cerebral cortex $(\boldsymbol{C})$ revealed no differences in the numbers of resting, activated, and total microglia between SCl and uninjured mice. $n=4(\mathrm{Sham}), n=5$ (SCI/Vehicle), $n=5$ (SCl/CR8).

genesis (Felix et al., 2012). The number of $\mathrm{DCX}^{+}$neurons in the DG showed a significant reduction at 12 weeks after SCI compared with control, uninjured animals ( $p<0.01$; Fig. 11), which is consistent with a previous report using cervical SCI in the adult rat (Felix et al., 2012). This reduction was significantly reversed by CR8 treatment.

We also evaluated the effects of SCI on plasticity-associated genes including brain-derived neurotrophic factor (BDNF),
cAMP response element-binding protein (CREB), synapsin 1, and insulin-like growth factor-1 (IGF-1). Hippocampal tissue was obtained from Sham or SCI brains at 12 weeks after injury and was used for qRT-PCR analysis. SCI did not alter synapsin 1 (Sham, $1.00 \pm 0.02, n=5$, vs SCI, $0.94 \pm 0.07, n=9$ ), BDNF (Sham, $1.00 \pm 0.01, n=5$, vs SCI, $1.05 \pm 0.02, n=9$ ), and CREB gene expression (Sham, $1.00 \pm 0.03, n=5$, vs SCI, $1.06 \pm 0.02$, $n=9$ ). In contrast, SCI modestly upregulated IGF-1 (SCI, $1.10 \pm$ 


\section{A Hippocampus}
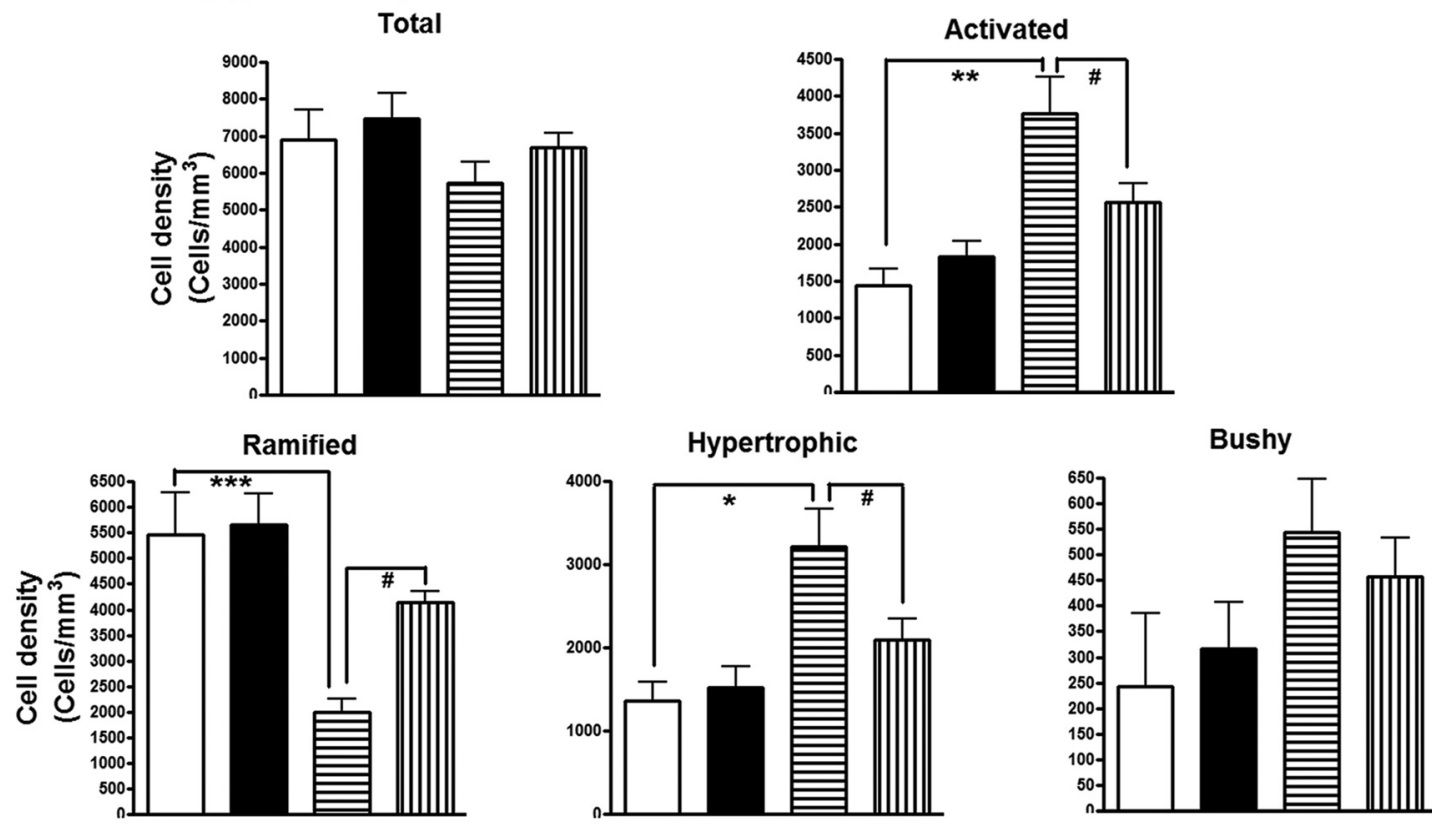

\section{B Cerebral cortex}
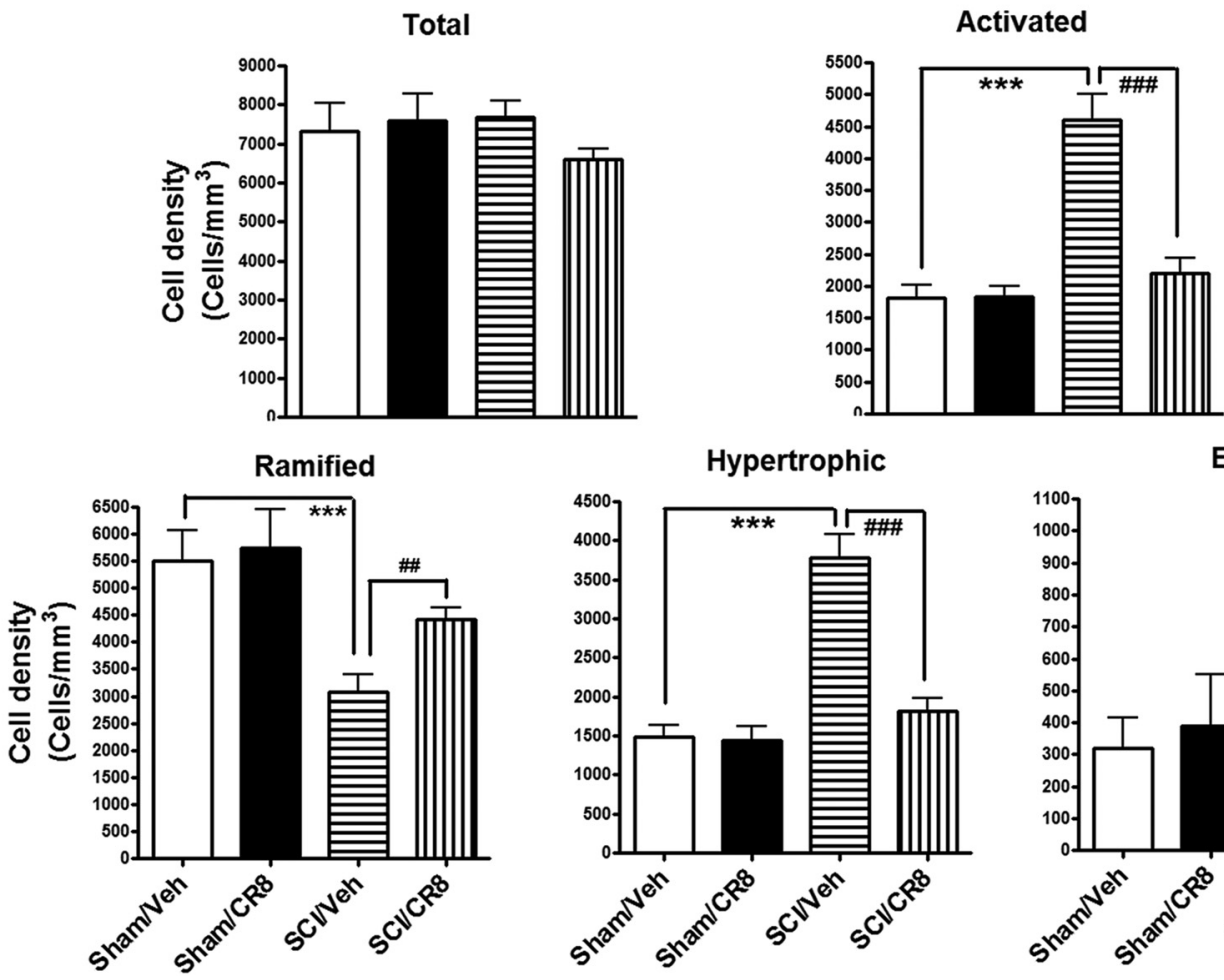

Hypertrophic

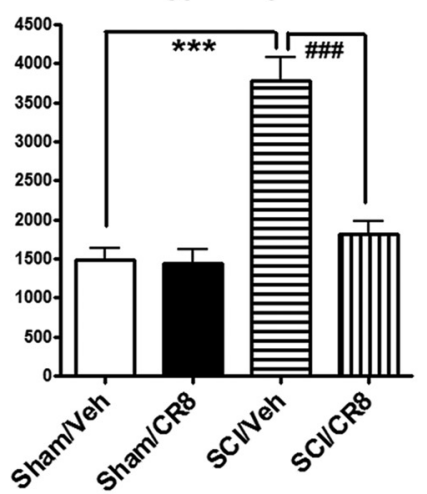

Bushy

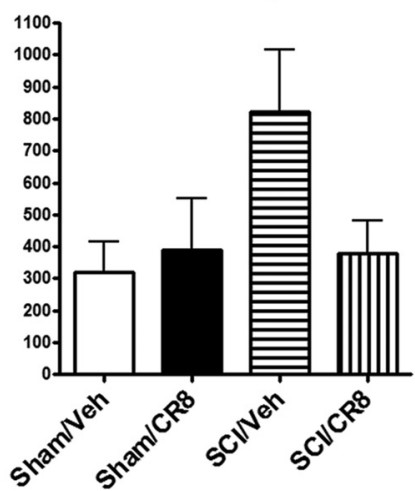

Figure 8. Chronic SCl increased activated microglial phenotypes in the brain at 12 weeks after lesion. Unbiased stereological quantitative assessment in the hippocampus ( $\boldsymbol{A}$ ) and cerebral cortex $(\boldsymbol{B})$ revealed increased numbers of highly activated microglia displaying a hypertrophic and bushy cellular morphology and reduced numbers of resting microglia displaying the ramified cellular morphology in SCI/Vehicle mice compared with Sham/Vehicle mice. CR8 treatment reversed these changes. ${ }^{*} p<0.05,{ }^{* *} p<0.01,{ }^{* * *} p<0.001, \mathrm{SCI} /$ Vehicle versus Sham/Vehicle groups; \#p $<$ 0.05, \#\#p <0.01,\#\#\# <0.001, SCI/CR8 versus SCI/Vehicle groups. $n=4$ (Sham/Vehicle), $n=4$ (Sham/CR8), $n=8$ (SCI/Vehicle), $n=10$ (SCI/CR8).

$0.02, n=9$, vs Sham, $1.00 \pm 0.02, n=5 ; p<0.05)$ gene expression in the hippocampus compared with the Sham tissues.

SCI causes upregulation of cell cycle genes and proteins in the hippocampus and cerebral cortex

To further investigate the involvement of the cell cycle pathway in SCI-induced brain abnormalities, we first examined whether up- regulation of cell cycle genes occurs in the brain after SCI. qRTPCR analysis showed an upregulation of a cluster of cell cycle related genes (cyclins A1, A2, and D1 as well as E2F1 and PCNA) in the hippocampus over the course of a few months after SCI (Fig. 12). Among them, the E2F1 transcription factor showed a rapid, transient elevation at $24 \mathrm{~h}$ after injury (Fig. 12A), consistent with our previous report in the injured spinal cord (Wu et al., 
A
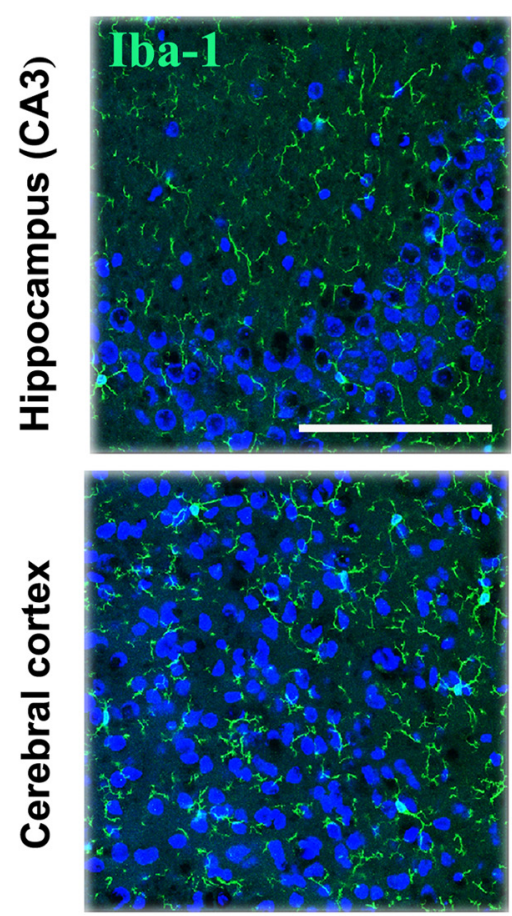

$\mathrm{SCl}$
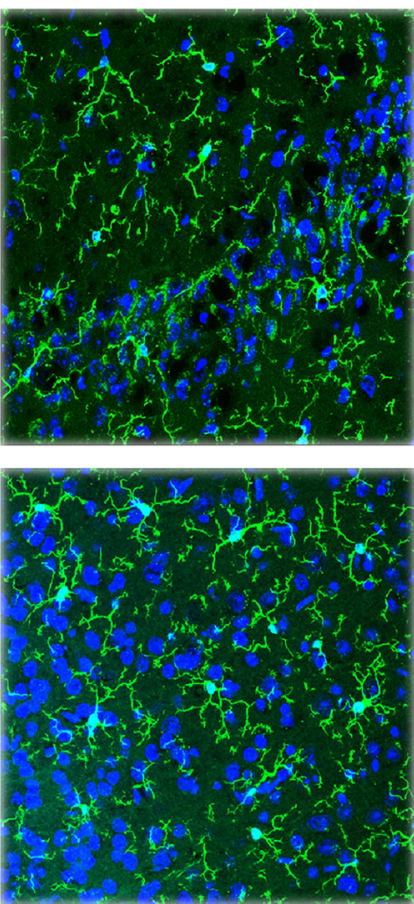

CR8
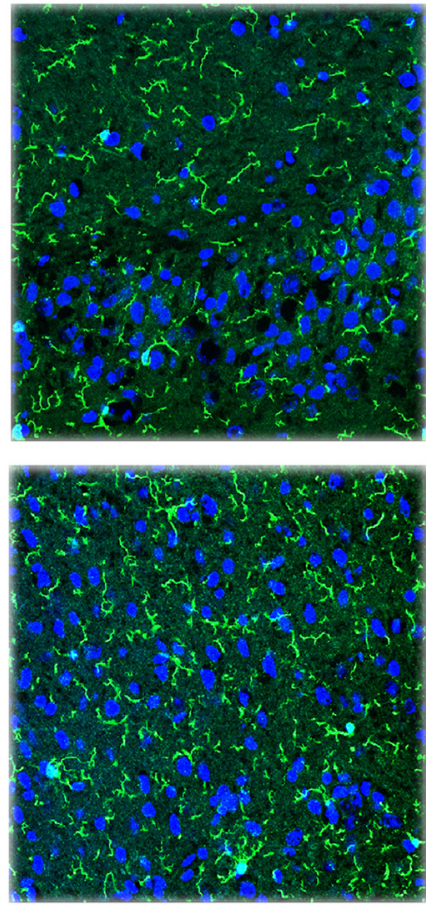

B
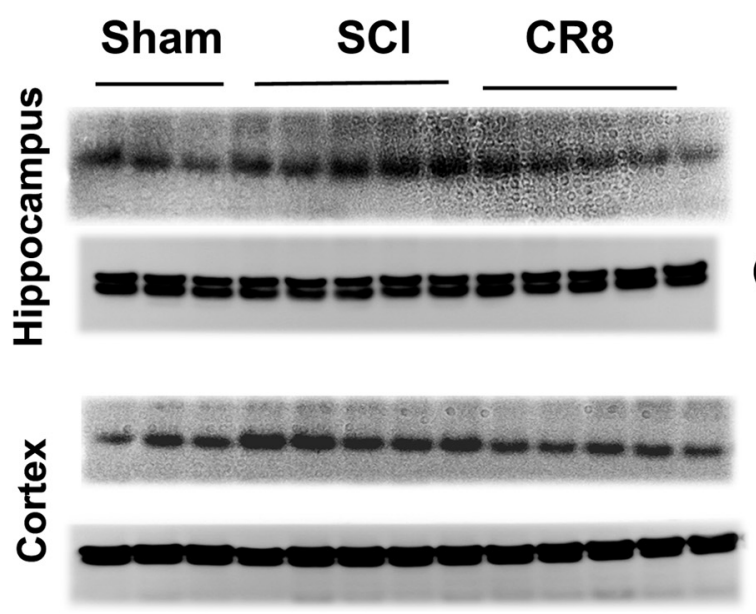

C

Iba-1 (Hippocampus)

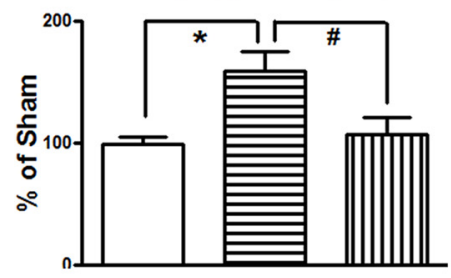

Iba-1 (Cortex)

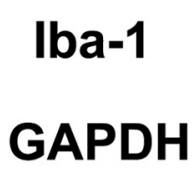

Iba-1

GAPDH

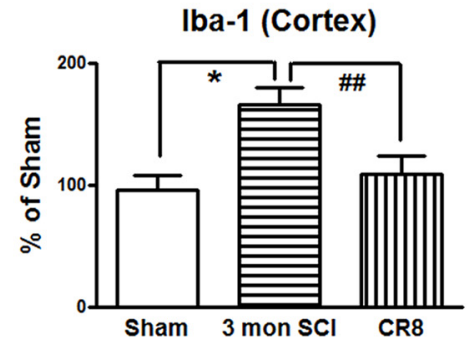

Figure 9. Iba-1 expression in the brain subregions after SCI was examined by $\mathrm{IHC}$ and Western blot. $A$, Representative Iba- 1 immunofluorescent images showed that SCl increased total numbers of microglia exhibiting marked cellular hypertrophy and retraction of processes in both hippocampus (CA3) and cerebral cortex at 12 weeks after injury and such changes were limited by CR8 treatment. Scale bars, $100 \mu \mathrm{m}$. B, Representative Western blots for the Iba-1 expression and the loading control (GAPDH). C, Quantification of the protein band intensity showed significantly increased expression of Iba-1 in the hippocampus and cerebral cortex at 12 weeks after injury, whereas CR8 treatment reversed elevation of Iba- 1 expression. ${ }^{*} p<0.05$ versus Sham mice; $\# p<$ $0.05, \# p<0.01$ versus 3 mon SCl. $n=5$ (Sham), $n=8$ (3mon SCl), $n=7$ (CR8).

2012c). mRNA levels of the cyclin A1, A2, D1, and PCNA genes were significantly increased in the SCI mice at $8 \mathrm{~d}$ after injury and PCNA gene expression increased further at 12 weeks after SCI (Fig. $12 B, C$ and $E, F$ ), whereas cyclin $B 1$ remained unchanged at all time points (Fig. 12D). Next, IHC was performed to determine the distribution of cyclin D1 in the brain after SCI (Fig. 13A). In the intact hippocampus and cerebral cortex, immunoreactivity of cyclin D1 was weakly detected in some neurons. At 12 weeks after injury, numerous cyclin-D1-positive cells were observed in both of these brain regions. Furthermore, Western blot analyses in 12 week SCI tissue revealed increased protein expression of cyclin D1 and CDK4 in both hippocampus and cerebral cortex (Fig. 13 B, C). Systemic administration of CR8 significantly suppressed SCI-mediated upregulation of cell cycle genes and protein expression in the brain.

\section{Discussion}

Using a mouse spinal cord contusion model, we demonstrate here that injury causes not only long-term locomotor deficits, but 

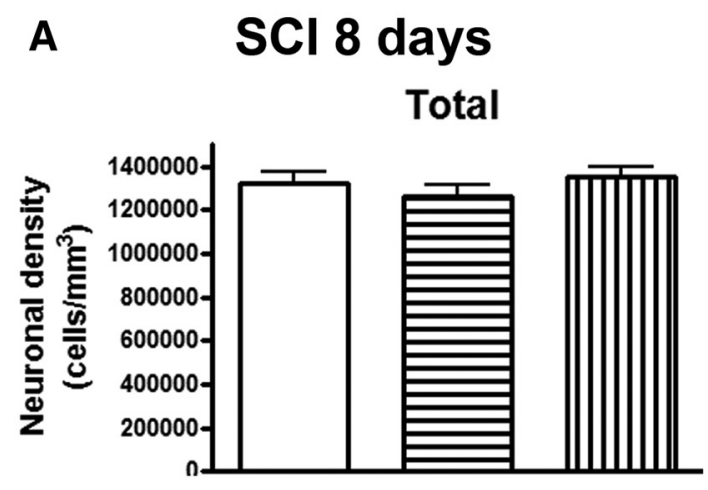

CA2/3

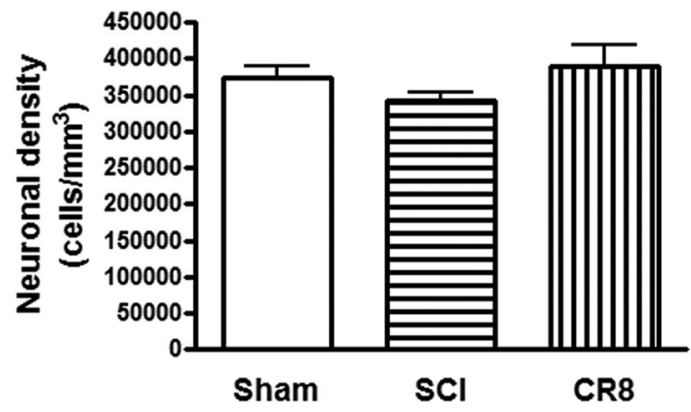

B SCl 3 months


CA1

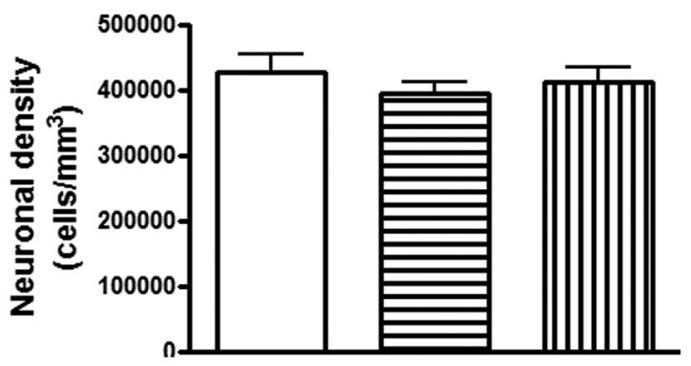

Dentate gyrus

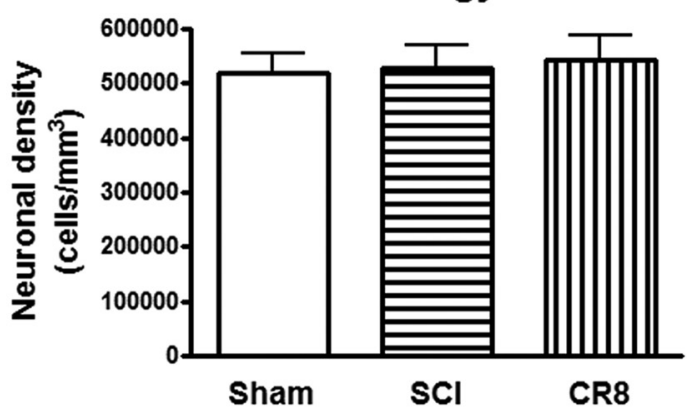

CA1
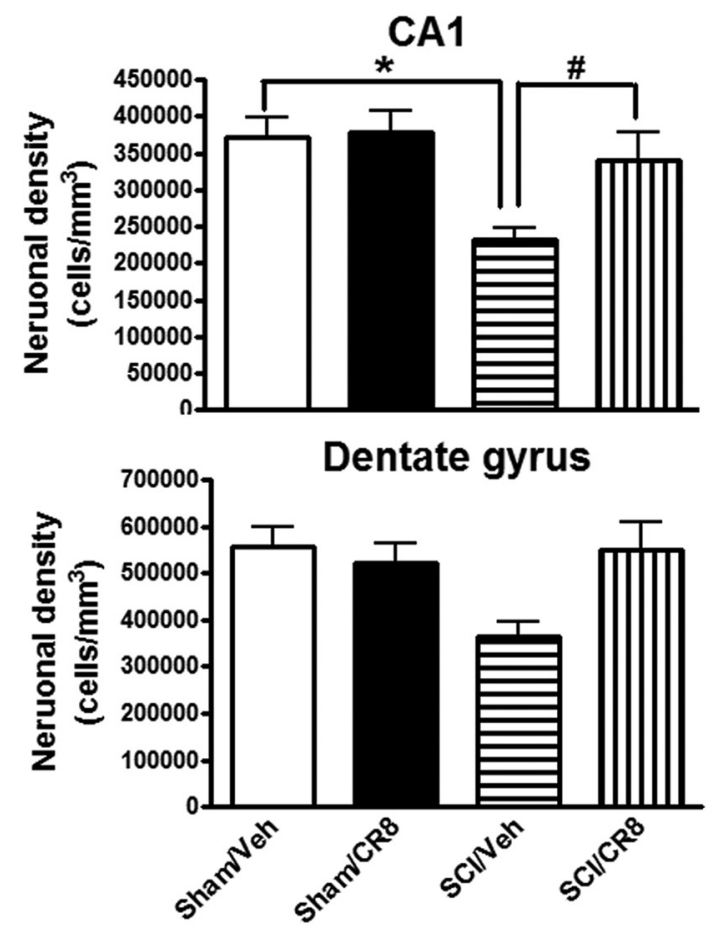

Figure 10. SCI-mediated chronic hippocampal neurodegeneration. Unbiased stereological techniques were used to quantify surviving neurons in the CA1, CA2/3, and DG subregions of the hippocampus in cresyl-violet-stained brain sections from Sham or SCI mice at $8 \mathrm{~d}$ or 12 weeks after injury. $A, A t 8 \mathrm{~d}$ after SCl, no differences were observed in the number of neurons across the groups. $n=4(\mathrm{Sham}), n=5(\mathrm{SCl}), n=5$ (CR8). B, SCl resulted in significant neuronal cell loss in the hippocampus at 12 weeks after injury. Systemic administration of CR8 significantly improved neuronal survival compared with SCI/Vehicle samples. ${ }^{*} p<0.05$ versus Sham/Vehicle mice; $\# p<0.05$, \#\#p $<0.01$ versus SCI/CR8. $n=5$ (Sham/Vehicle), $n=4$ (Sham/CR8), $n=9$ (SCI/Vehicle), $n=10$ (SCI/CR8).

also cognitive changes and depressive-like behaviors; the latter changes are associated with increased numbers of reactive microglia and neuronal loss in the hippocampus and cerebral cortex. Increased expression of cell cycle genes and proteins was also found in these regions after SCI. Each of these changes was atten- uated by inhibition of cell cycle pathways, suggesting that CCA contributes to such delayed pathophysiological events.

A battery of cognitive and sensorimotor behavioral assessments were used to reduce the potential confounding effects of motor dysfunction. The MWM has been used commonly to ex- 


\section{A}

\section{Doublecortin/DAP}
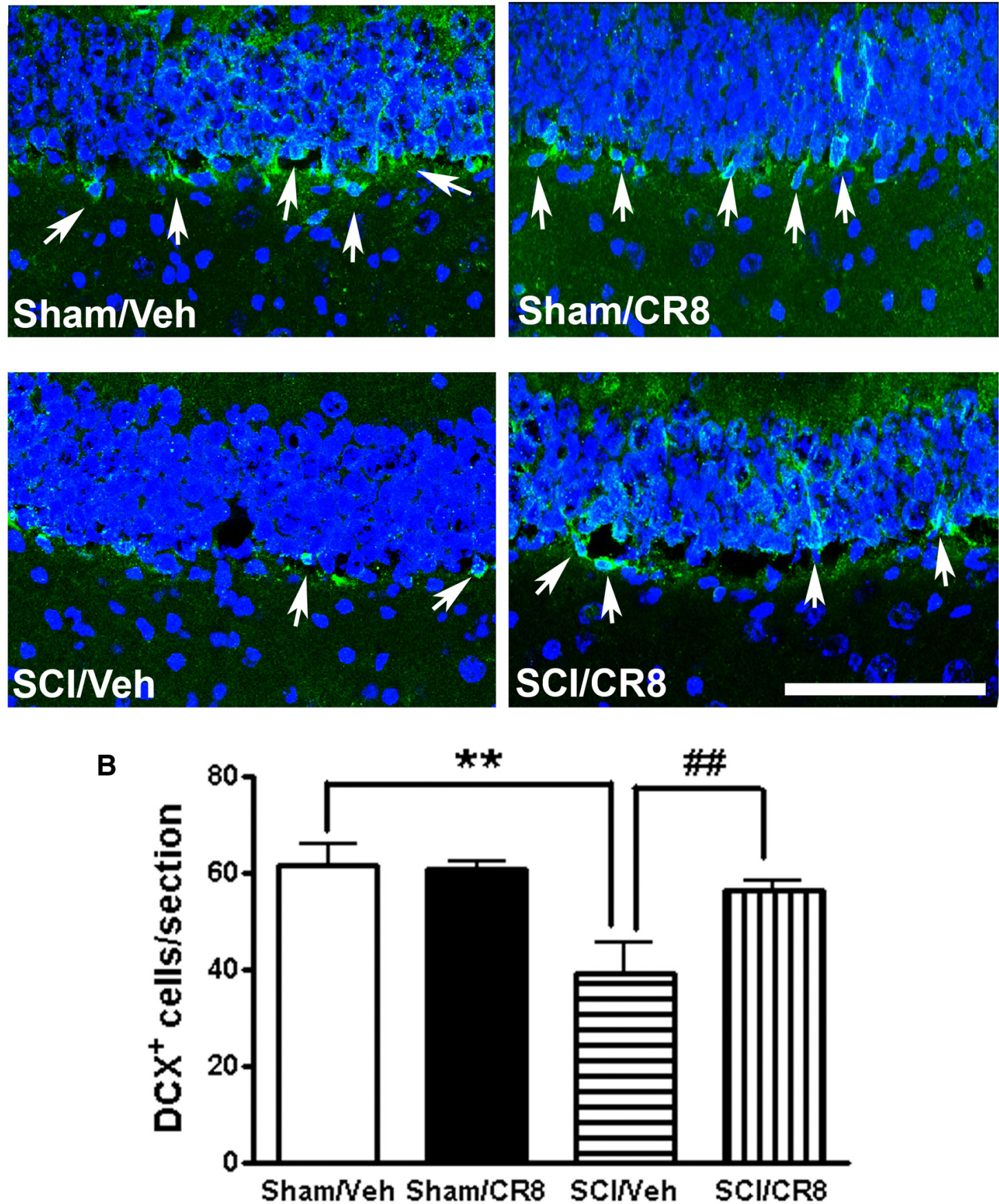

Figure 11. Distribution and quantification of immature neurons in the adult $D G$ after $S C I$. $A$, Representative images showed doublecortin (DCX, green, white arrows) and nuclear staining (DAPI, blue) in the hippocampal DG subregion. Scale bar, $100 \mu \mathrm{m}$. B, Quantification of the number of DCX+ ${ }^{+}$cells per DG in a $20 \mu \mathrm{m}$ section. SCI caused a significant $36 \%$ reduction of DCX ${ }^{+}$cells at 12 weeks after injury compared with Sham samples. CR8-treated mice showed significantly increased DCX ${ }^{+}$cells in the DG. $n=5$ images/DG/mouse/6 mice/group. ${ }^{* *} p<0.01$ versus Sham/Vehicle mice; $\# \#<0.01$ versus $\mathrm{SCI} /$ Vehicle.

amine hippocampus-dependent spatial learning and memory impairments in rodents. However, despite a certain level of motor recovery, injured mice showed significantly reduced swim speeds and distance, decreased activity in the OF, and increased immobility time in the TS. Therefore, observing delayed escape latency and less time spent in target quadrant may not reflect pure cognitive deficits, but may be confounded by motor and affective impairments. Therefore, we also examined the search strategy used by the injured mice to locate the hidden platform, a method used previously by us for both the Barnes maze and MWM tests after TBI (Fox et al., 1998; Zhao et al., 2012). This strategy provides complementary outcome measures that may be less dependent on motor function. Sham-injured mice primarily employ a spatial strategy to locate the platform; use of this strategy decreased after SCI. Moreover, whereas Sham animals swam in the center of the maze to find the hidden platform, injured animals spent most of their time swimming around the entrance quadrant of the maze. The Y-maze, NOR, and SDPA tests are also less 
dependent on locomotion, reflecting both frontal cortical and hippocampal function as well as a fear-motivated learning task. Injured mice showed significantly impaired performance in these tests compared with Sham mice. Collectively, these results indicate that SCI causes learning and memory impairment. Only one prior experimental study has suggested cognitive decline after SCI: a projectile injury in pigs wearing body armor (Zhang et al., 2011). However, the model, species, and outcome used (conditioned feeding behavior) makes both interpretation and relevant comparison difficult. It has been suggested previously that trauma induced with body armor may allow transmission of forces more directly to brain, including through large vessels, and injured pigs showed nearly immediate changes in electroencephalogram and intracranial pressure, suggesting that the model may reflect direct brain injury as well as SCI.

Many clinical studies have reported post-SCI depression, which has been assumed to be situational or reactive. Our data suggest that SCI can result in a physiological depression that can be modified by inhibiting the posttraumatic inflammatory response. CR8 treatment significantly increased sweet water consumption in the SP test, but did not alter plain drinking water and food consumption. The lack of changes in food consumption suggests that factors such as locomotion-dependent changes in metabolisms do not play a major role in the post-SCI depression-like symptoms. Therefore, our data strongly suggest that such depression may in part reflect ongoing pathophysiological changes in the brain and require different treatment approaches than antidepressant strategies.

Microglial activation has long been linked to changes in cognitive function through both direct and indirect effects on neurons. Two recent clinical studies, one using PET scanning to delineate microglial activity and the other pathological, have further underscored the importance of microglial activation in chronic neurodegeneration after TBI (Ramlackhansingh et al., 2011; Johnson et al., 2013). We used real-time qRT-PCR, stereological microglial phenotype counts, IHC, and Western blot analyses to show that SCI caused chronic microglial activation in the brain. CNS resident microglia, like peripheral macrophages, have multiple activation phenotypes (Gordon, 2003). The neurotoxic reactive phenotype (M1) is characterized by increased expression of proinflammatory cytokines, reactive oxygen species, and nitric oxide, contributing to tissue inflammation and damage (Lynch, 2009). Here, we show that SCI induced significant increases of M1 microglial activation genes and $\mathrm{MHC}$ II expression in the hippocampus. After SCI, the proinflammatory cytokine IL6 was also increased in the thalamus, as shown previously (Zhao et al., 2007), and in the hippocampus, as shown
E2F1

B cyclin A1

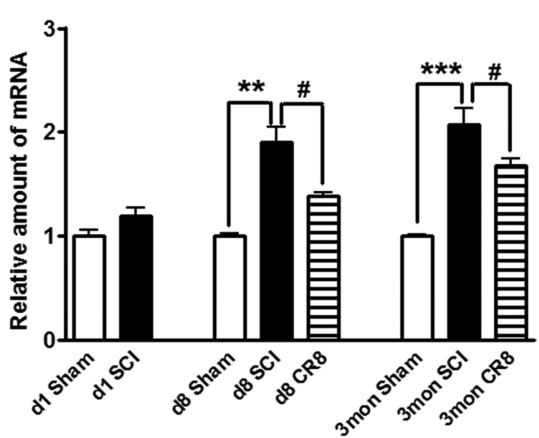

D

cyclin B1

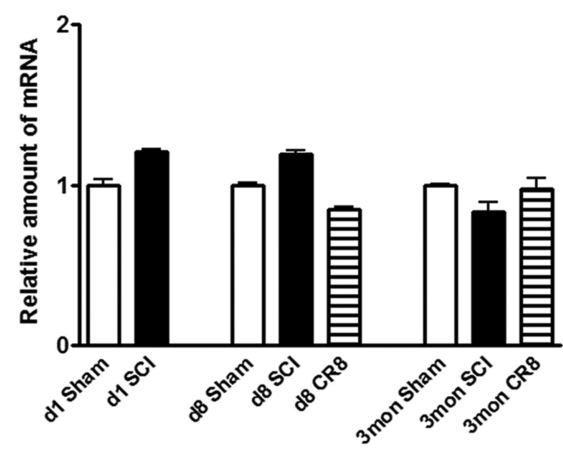

$F$

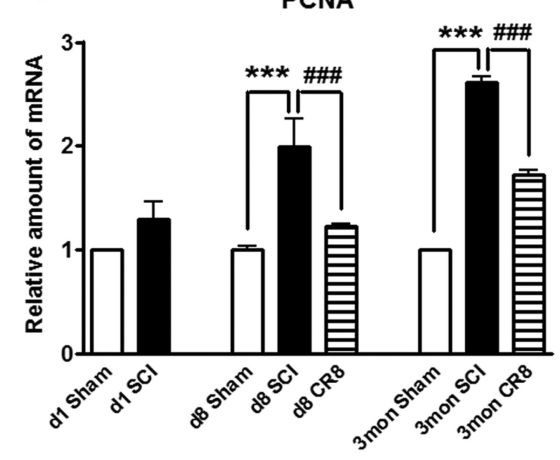

Figure 12. Effect of impact SCl on the expression of a cluster of cell cycle genes in the hippocampus. qRT-PCR analysis was used to quantify mRNA levels in the hippocampal tissues from Sham or SCI mice at $1 \mathrm{~d}, 8 \mathrm{~d}$, or 12 weeks after injury. The E2F1 transcription factor $(\boldsymbol{A})$ showed a rapid, transient elevation at $24 \mathrm{~h}$ after injury. The expression of cyclin A1, A2, D1, and PCNA genes , $\boldsymbol{F}$ ) were significantly increased in the $S C I$ mice at $8 \mathrm{~d}$ after injury and $\mathrm{PCNA}$ gene expression increased further at 12 weeks after $\mathrm{SCI}(\boldsymbol{F})$, whereas cyclin B1 remained unchanged at all time points $(\boldsymbol{D}) .{ }^{*} p<0.05,{ }^{* *} p<0.01,{ }^{* * *} p<0.001$ versu Sham groups; \#p $<0.05$, \#\#\#p $<0.001$ versus SCl groups. $n=3$ (d1 Sham), $n=5$ (d1 SCl), $n=3$ (d8Sham), $n=5$ (d8SCl), $n=$ 5 (d8 CR8), $n=5$ (3mon Sham), $n=9$ (3mon SCl), $n=7$ (3mon CR8).

here. IL6 has a dual role as a microglial activator as well as a neuromodulator (Milligan et al., 2005; Schoeniger-Skinner et al., 2007). Guerrero et al. (2012) reported that blocking IL6 signaling promotes functional recovery by inhibiting M1 and promoting M2 macrophage activation after SCI. In contrast, the M2 phenotype microglia secretes anti-inflammatory cytokines and neurotrophic factors, thereby contributing to wound healing and tissue remodeling. Although we did not observe any difference in M2a and M2c markers in the SCI brain, the anti-inflammatory cytokine IL10 is reported to promote a M2c phenotype that is immunosuppressive (Colton, 2009). SCI enhanced IL10 gene expression in the hippocampus.

The relative interactions among SCI, hypotension, and anesthetic effects could potentially contribute to brain changes after SCI. Although we and others have measured blood pressure after 
A
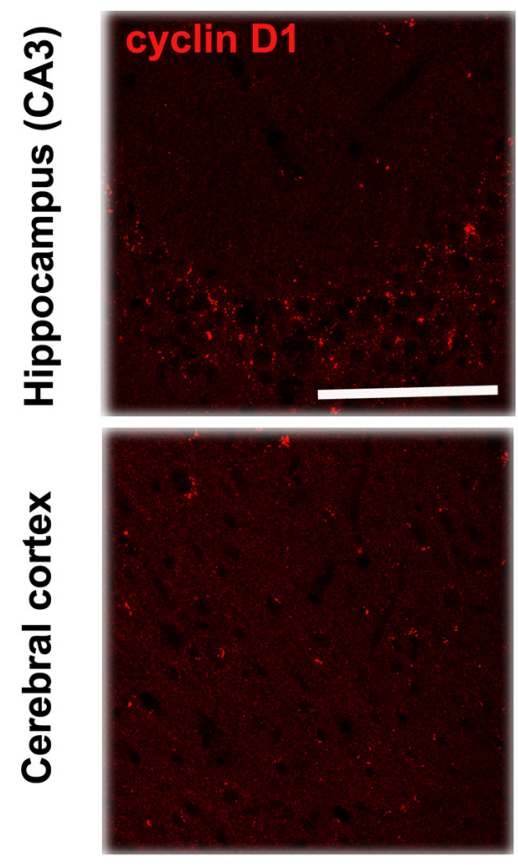

SCI


CR8
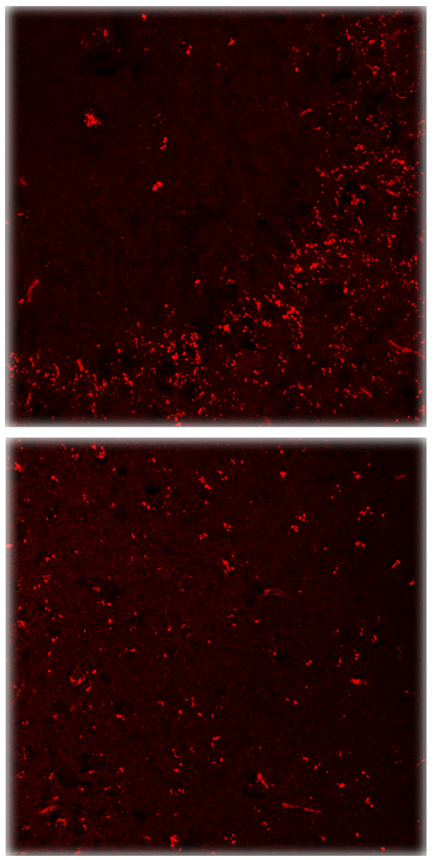

B
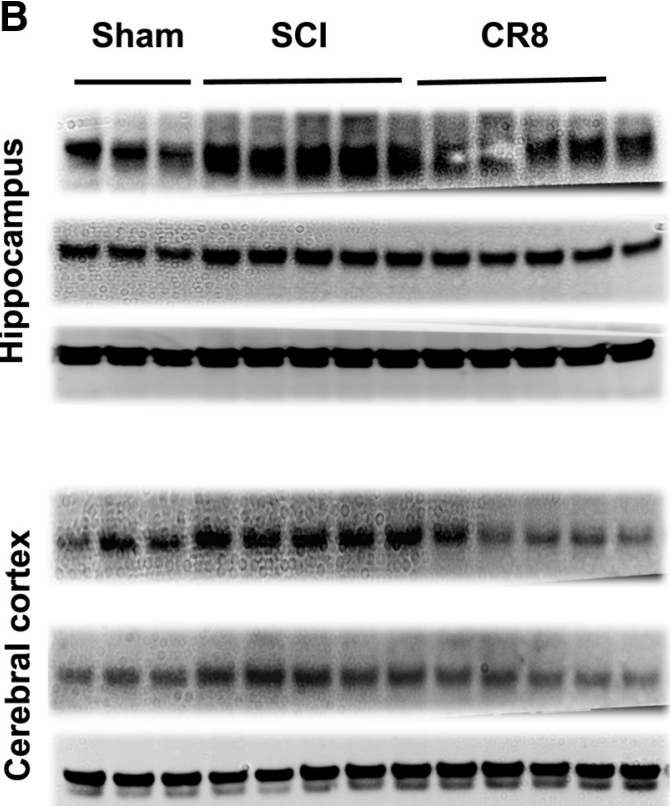

cyclin D1

CDK4

GAPDH

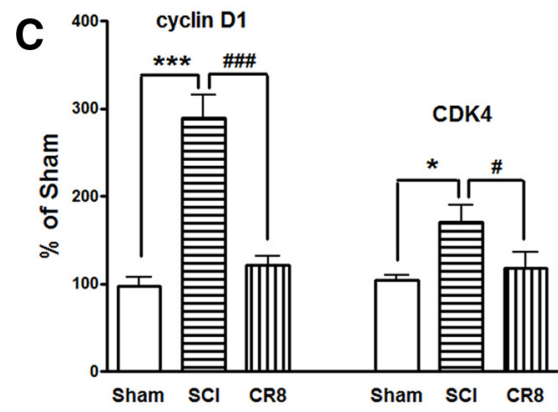

cyclin D1

CDK4

GAPDH

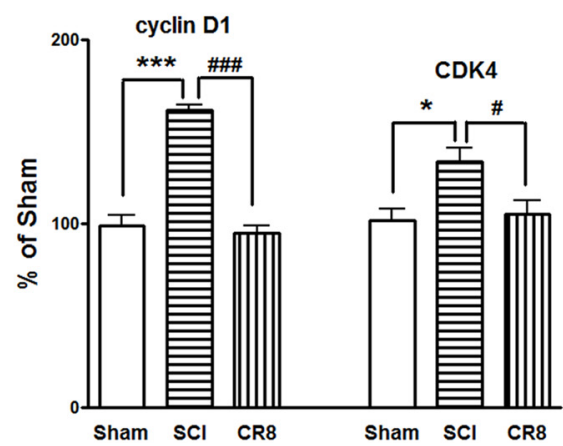

Figure 13. SCI causes upregulation of cyclin D1 and CDK4 proteins in the hippocampus and cerebral cortex at 12 weeks after injury. $A$, Representative cyclin D1 immunofluorecent images showing that SCl increased the total numbers of cyclin D1 ${ }^{+}$cells in both hippocampus (CA3) and cerebral cortex at 12 weeks after injury and such changes were limited by CR8 treatment. Scale bars, $100 \mu \mathrm{m}$. $B$, Representative Western blots for the cyclin D1 and CDK4 expression and the loading control (GAPDH). C, Quantification of protein band intensity showing significantly increased expression of cyclin D1 and CDK4 in the hippocampus and cerebral cortex at 12 weeks after injury, whereas CR8 treatment reversed elevation of cyclin D1 and CDK4 expression. ${ }^{*} p<0.05$, ${ }^{* * *} p<0.001$ versus Sham mice; $\# p<0.05$, \#\#\#p $<0.001$ versus SCl group. $n=5$ (Sham), $n=8$ (SCI), $n=7$ (CR8).

SCI in cats and rats, this is rarely attempted in mouse models for technical reasons. However, hypotension after SCI reaches significant levels primarily after cervical or high thoracic injuries, which are rostral to spinal sympathetic cardiovascular regulatory sites (T1-T4). Our injury was performed at T9, in part to exclude such complications. Nout et al. (2012)recently examined effects of anesthetics and thoracic SCI on blood pressure in rats. At a moderate injury levels, SCI with isoflurane anesthesia produced only modest, transitory hypotension. Such changes would not be expected to cause chronic brain hypoxic injury. Moreover, the injury used was at $\mathrm{T} 1$, which would cause far more changes than at T9. Most importantly, were such early hypoxia to occur, it would lead to acute neuronal loss within the first days of injury. We found no neuronal loss in the hippocampus at $8 \mathrm{~d}$ after injury, underscoring the delayed progressive nature of our observed changes. 
SCI also induces compensatory anatomical plasticity. Endo et al. (2007) reported that the Nogo receptor and its coreceptor, LINGO-1, are downregulated in cortical areas deprived of sensory input and in adjacent cortex after complete thoracic spinal transection, whereas BDNF is upregulated. Further, synapsin expression and neurite sprouting are increased in lamprey brain after spinal cord transections (Lau et al., 2011). In contrast, acute $\mathrm{SCI}$ in rats reduces $\mathrm{BDNF}$ levels in the hippocampus in conjunction with the activated forms of synapsin 1, CREB, and CaMKII (Fumagalli et al., 2009; Gomez-Pinilla et al., 2012). In our model, SCI did not alter synapsin, BDNF, or CREB gene expression in hippocampus at 12 weeks after injury, although IGF-1 gene expression was increased modestly.

The role of CCA in the pathophysiology of SCI has been studied extensively by us and others, with most work focusing on primary lesion site (Di Giovanni et al., 2003; Tian et al., 2007; Wu et al., 2011; Wu et al., 2012b). More recently, we demonstrated that CCA contributes to remote microglial activation after thoracic contusion SCI, including the thalamus and lumbar spinal dorsal horn, as evidenced by reduction of microglia activation in these areas after CCA inhibition (Wu et al., 2013a; Wu et al., 2013b). Our previous data in SCI and TBI models in vivo, as well as microglia in vitro, have shown that cell cycle inhibitors, including CR8, potently and directly attenuate neuroinflammation (Di Giovanni et al., 2005; Byrnes et al., 2007; Hilton et al., 2008; Kabadi et al., 2012a; Kabadi et al., 2012b; Wu et al., 2012b; Wu et al., 2013a; Wu et al., 2013b; Kabadi et al., 2014). The effects are based on the involvement of cell cycle initiation in microglia activation.

The mechanisms underlying SCI-mediated effects in brain remain speculative. SCI can cause reorganization of the cerebral cortex, as well as thalamus, through anterograde and retrograde mechanisms (Nardone et al., 2013). Previous anatomical and experimental studies have demonstrated that the thalamic nucleus sends some of its major cortical efferents to the hippocampal formation (Cavdar et al., 2008). Distal release of cysteine-cysteine chemokine ligand 21, synthesized by damaged neurons in spinal cord after injury, has been proposed as a molecular mechanism that triggers microglial activation at distant spinal segments and the thalamus (Zhao et al., 2007; Hulsebosch et al., 2009). SCI can also alter systemic immune functions (Ankeny and Popovich, 2009) that can secondarily affect the brain. It is also possible that factors are released that have access to the brain through the CSF.

In summary, using a well characterized mouse model, we show that $\mathrm{SCI}$ induces chronic neuroinflammation and neurodegeneration in brain. Changes are remarkably similar to what has been observed after TBI both experimentally and clinically: progressive neurodegeneration in the brain associated with cognitive decline and physiological depression. These findings, if confirmed clinically, would considerably revise concepts about the nature of SCI as a focal acute neurodegenerative disorder. That cell cycle inhibition can limit each of these changes offers the potential for a targeted clinical therapy that can potentially block many of the important functional consequences of SCI. In addition, the finding that CCA continues chronically after SCI in each of the regions associated with long-term progressive consequences of injury may permit treatment with a far greater therapeutic window than previously considered.

\section{References}

Ankeny DP, Popovich PG (2009) Mechanisms and implications of adaptive immune responses after traumatic spinal cord injury. Neuroscience 158: 1112-1121. CrossRef Medline
Baratz R, Rubovitch V, Frenk H, Pick CG (2010) The influence of alcohol on behavioral recovery after mTBI in mice. J Neurotrauma 27:555-563. CrossRef Medline

Basso DM, Fisher LC, Anderson AJ, Jakeman LB, McTigue DM, Popovich PG (2006) Basso Mouse Scale for locomotion detects differences in recovery after spinal cord injury in five common mouse strains. J Neurotrauma 23:635-659. CrossRef Medline

Bonatz H, Röhrig S, Mestres P, Meyer M, Giehl KM (2000) An axotomy model for the induction of death of rat and mouse corticospinal neurons in vivo. J Neurosci Methods 100:105-115. CrossRef Medline

Byrnes KR, Stoica BA, Fricke S, Di Giovanni S, Faden AI (2007) Cell cycle activation contributes to post-mitotic cell death and secondary damage after spinal cord injury. Brain 130:2977-2992. CrossRef Medline

Byrnes KR, Loane DJ, Stoica BA, Zhang J, Faden AI (2012) Delayed mGluR5 activation limits neuroinflammation and neurodegeneration after traumatic brain injury. J Neuroinflammation 9:43. CrossRef Medline

Cavdar S, Onat FY, Cakmak YO, Yananli HR, Gülçebi M, Aker R (2008) The pathways connecting the hippocampal formation, the thalamic reuniens nucleus and the thalamic reticular nucleus in the rat. J Anat 212:249-256. CrossRef Medline

Colton CA (2009) Heterogeneity of microglial activation in the innate immune response in the brain. J Neuroimmune Pharmacol 4:399-418. CrossRef Medline

Crawley AP, Jurkiewicz MT, Yim A, Heyn S, Verrier MC, Fehlings MG, Mikulis DJ (2004) Absence of localized grey matter volume changes in the motor cortex following spinal cord injury. Brain Res 1028:19-25. CrossRef Medline

Cryan JF, Mombereau C, Vassout A (2005) The tail suspension test as a model for assessing antidepressant activity: review of pharmacological and genetic studies in mice. Neurosci Biobehav Rev 29:571-625. CrossRef Medline

Di Giovanni S, Knoblach SM, Brandoli C, Aden SA, Hoffman EP, Faden AI (2003) Gene profiling in spinal cord injury shows role of cell cycle in neuronal death. Ann Neurol 53:454-468. CrossRef Medline

Di Giovanni S, Movsesyan V, Ahmed F, Cernak I, Schinelli S, Stoica B, Faden AI (2005) Cell cycle inhibition provides neuroprotection and reduces glial proliferation and scar formation after traumatic brain injury. Proc Natl Acad Sci U S A 102:8333-8338. CrossRef Medline

Endo T, Spenger C, Tominaga T, Brené S, Olson L (2007) Cortical sensory map rearrangement after spinal cord injury: fMRI responses linked to Nogo signalling. Brain 130:2951-2961. CrossRef Medline

Felix MS, Popa N, Djelloul M, Boucraut J, Gauthier P, Bauer S, Matarazzo VA (2012) Alteration of forebrain neurogenesis after cervical spinal cord injury in the adult rat. Front Neurosci 6:45. CrossRef Medline

Feringa ER, Vahlsing HL (1985) Labeled corticospinal neurons one year after spinal cord transection. Neurosci Lett 58:283-286. CrossRef Medline

Fox GB, Fan L, LeVasseur RA, Faden AI (1998) Effect of traumatic brain injury on mouse spatial and nonspatial learning in the Barnes circular maze. J Neurotrauma 15:1037-1046. CrossRef Medline

Fumagalli F, Madaschi L, Caffino L, Marfia G, Di Giulio AM, Racagni G, Gorio A (2009) Acute spinal cord injury reduces brain derived neurotrohic factor expression in rat hippocampus. Neuroscience 159:936939. CrossRef Medline

Ganchrow D, Bernstein JJ (1985) Thoracic dorsal funicular lesions affect the bouton patterns on, and diameters of, layer VB pyramidal cell somata in rat hindlimb cortex. J Neurosci Res 14:71-81. CrossRef Medline

Giehl KM, Tetzlaff W (1996) BDNF and NT-3, but not NGF, prevent axotomy-induced death of rat corticospinal neurons in vivo. Eur J Neurosci 8:1167-1175. CrossRef Medline

Gomez-Pinilla F, Ying Z, Zhuang Y (2012) Brain and spinal cord interaction: protective effects of exercise prior to spinal cord injury. PLoS One 7:e32298. CrossRef Medline

Gordon S (2003) Alternative activation of macrophages. Nat Rev Immunol 3:23-35. CrossRef Medline

Gresack JE, Kerr KM, Frick KM (2007) Life-long environmental enrichment differentially affects the mnemonic response to estrogen in young, middle-aged, and aged female mice. Neurobiol Learn Mem 88:393-408. CrossRef Medline

Guerrero AR, Uchida K, Nakajima H, Watanabe S, Nakamura M, Johnson WE, Baba H (2012) Blockade of interleukin-6 signaling inhibits the classic pathway and promotes an alternative pathway of macrophage activa- 
tion after spinal cord injury in mice. J Neuroinflammation 9:40. CrossRef Medline

Hains BC, Black JA, Waxman SG (2003) Primary cortical motor neurons undergo apoptosis after axotomizing spinal cord injury. J Comp Neurol 462:328-341. CrossRef Medline

Hains BC, Saab CY, Waxman SG (2005) Changes in electrophysiological properties and sodium channel Nav1.3 expression in thalamic neurons after spinal cord injury. Brain 128:2359-2371. CrossRef Medline

Hammond EN, Tetzlaff W, Mestres P, Giehl KM (1999) BDNF, but not NT-3, promotes long-term survival of axotomized adult rat corticospinal neurons in vivo. Neuroreport 10:2671-2675. CrossRef Medline

Hilton GD, Stoica BA, Byrnes KR, Faden AI (2008) Roscovitine reduces neuronal loss, glial activation, and neurologic deficits after brain trauma. J Cereb Blood Flow Metab 28:1845-1859. CrossRef Medline

Hong M, Zheng J, Ding ZY, Chen JH, Yu L, Niu Y, Hua YQ, Wang LL (2013) Imbalance between Th17 and Treg cells may play an important role in the development of chronic unpredictable mild stress-induced depression in mice. Neuroimmunomodulation 20:39-50. CrossRef Medline

Huang FL, Huang KP, Wu J, Boucheron C (2006) Environmental enrichment enhances neurogranin expression and hippocampal learning and memory but fails to rescue the impairments of neurogranin null mutant mice. J Neurosci 26:6230-6237. CrossRef Medline

Hubscher CH, Johnson RD (2006) Chronic spinal cord injury induced changes in the responses of thalamic neurons. Exp Neurol 197:177-188. CrossRef Medline

Hulsebosch CE, Hains BC, Crown ED, Carlton SM (2009) Mechanisms of chronic central neuropathic pain after spinal cord injury. Brain Res Rev 60:202-213. CrossRef Medline

Johnson VE, Stewart JE, Begbie FD, Trojanowski JQ, Smith DH, Stewart W (2013) Inflammation and white matter degeneration persist for years after a single traumatic brain injury. Brain 136:28-42. CrossRef Medline

Kabadi SV, Stoica BA, Byrnes KR, Hanscom M, Loane DJ, Faden AI (2012a) Selective CDK inhibitor limits neuroinflammation and progressive neurodegeneration after brain trauma. J Cereb Blood Flow Metab 32:137149. CrossRef Medline

Kabadi SV, Stoica BA, Hanscom M, Loane DJ, Kharebava G, Murray Ii MG, Cabatbat RM, Faden AI (2012b) CR8, a selective and potent CDK inhibitor, provides neuroprotection in experimental traumatic brain injury. Neurotherapeutics 9:405-421. CrossRef Medline

Kabadi SV, Stoica BA, Loane DJ, Luo T, Faden AI (2014) CR8, a novel inhibitor of CDK, limits microglial activation, astrocytosis, neuronal loss, and neurologic dysfunction after experimental traumatic brain injury. J Cereb Blood Flow Metab 34:502-513. CrossRef Medline

Klapka N, Hermanns S, Straten G, Masanneck C, Duis S, Hamers FP, Müller D, Zuschratter W, Müller HW (2005) Suppression of fibrous scarring in spinal cord injury of rat promotes long-distance regeneration of corticospinal tract axons, rescue of primary motoneurons in somatosensory cortex and significant functional recovery. Eur J Neurosci 22:3047-3058. CrossRef Medline

Knerlich-Lukoschus F, Noack M, von der Ropp-Brenner B, Lucius R, Mehdorn HM, Held-Feindt J (2011) Spinal cord injuries induce changes in $\mathrm{CB} 1$ cannabinoid receptor and C-C chemokine expression in brain areas underlying circuitry of chronic pain conditions. J Neurotrauma 28:619634. CrossRef Medline

Kumar A, Loane DJ (2012) Neuroinflammation after traumatic brain injury: opportunities for therapeutic intervention. Brain Behav Immun 26: 1191-1201. CrossRef Medline

Kumar A, Stoica BA, Sabirzhanov B, Burns MP, Faden AI, Loane DJ (2013) Traumatic brain injury in aged animals increases lesion size and chronically alters microglial/macrophage classical and alternative activation states. Neurobiol Aging 34:1397-1411. CrossRef Medline

Lau BY, Foldes AE, Alieva NO, Oliphint PA, Busch DJ, Morgan JR (2011) Increased synapsin expression and neurite sprouting in lamprey brain after spinal cord injury. Exp Neurol 228:283-293. CrossRef Medline

Lee HJ, Wu J, Chung J, Wrathall JR (2013) SOX2 expression is upregulated in adult spinal cord after contusion injury in both oligodendrocyte lineage and ependymal cells. J Neurosci Res 91:196-210. CrossRef Medline

Livak KJ, Schmittgen TD (2001) Analysis of relative gene expression data using real-time quantitative PCR and the 2(-Delta Delta C(T)) Method. Methods 25:402-408. CrossRef Medline

Lynch MA (2009) The multifaceted profile of activated microglia. Mol Neurobiol 40:139-156. CrossRef Medline
Mason MR, Lieberman AR, Anderson PN (2003) Corticospinal neurons up-regulate a range of growth-associated genes following intracortical, but not spinal, axotomy. Eur J Neurosci 18:789-802. CrossRef Medline

Merline M, Kalil K (1990) Cell death of corticospinal neurons is induced by axotomy before but not after innervation of spinal targets. J Comp Neurol 296:506-516. CrossRef Medline

Milligan E, Zapata V, Schoeniger D, Chacur M, Green P, Poole S, Martin D, Maier SF, Watkins LR (2005) An initial investigation of spinal mechanisms underlying pain enhancement induced by fractalkine, a neuronally released chemokine. Eur J Neurosci 22:2775-2782. CrossRef Medline

Murray RF, Asghari A, Egorov DD, Rutkowski SB, Siddall PJ, Soden RJ, Ruff R (2007) Impact of spinal cord injury on self-perceived pre- and postmorbid cognitive, emotional and physical functioning. Spinal Cord 45: 429-436. CrossRef Medline

Nardone R, Höller Y, Brigo F, Seidl M, Christova M, Bergmann J, Golaszewski S, Trinka E (2013) Functional brain reorganization after spinal cord injury: systematic review of animal and human studies. Brain Res 1504: 58-73. CrossRef Medline

Nielson JL, Sears-Kraxberger I, Strong MK, Wong JK, Willenberg R, Steward O (2010) Unexpected survival of neurons of origin of the pyramidal tract after spinal cord injury. J Neurosci 30:11516-11528. CrossRef Medline

Nielson JL, Strong MK, Steward O (2011) A reassessment of whether cortical motor neurons die following spinal cord injury. J Comp Neurol 519: 2852-2869. CrossRef Medline

Nout YS, Beattie MS, Bresnahan JC (2012) Severity of locomotor and cardiovascular derangements after experimental high-thoracic spinal cord injury is anesthesia dependent in rats. J Neurotrauma 29:990-999. CrossRef Medline

Ramlackhansingh AF, Brooks DJ, Greenwood RJ, Bose SK, Turkheimer FE, Kinnunen KM, Gentleman S, Heckemann RA, Gunanayagam K, Gelosa G, Sharp DJ (2011) Inflammation after trauma: microglial activation and traumatic brain injury. Ann Neurol 70:374-383. CrossRef Medline

Sabirzhanov B, Stoica BA, Hanscom M, Piao CS, Faden AI (2012) Overexpression of HSP70 attenuates caspase-dependent and caspaseindependent pathways and inhibits neuronal apoptosis. J Neurochem 123:542-554. CrossRef Medline

Schoeniger-Skinner DK, Ledeboer A, Frank MG, Milligan ED, Poole S, Martin D, Maier SF, Watkins LR (2007) Interleukin-6 mediates lowthreshold mechanical allodynia induced by intrathecal HIV-1 envelope glycoprotein gp120. Brain Behav Immun 21:660-667. CrossRef Medline

Sedgwick JD, Ford AL, Foulcher E, Airriess R (1998) Central nervous system microglial cell activation and proliferation follows direct interaction with tissue-infiltrating T cell blasts. J Immunol 160:5320-5330. Medline

Sierksma AS, van den Hove DL, Pfau F, Philippens M, Bruno O, Fedele E, Ricciarelli R, Steinbusch HW, Vanmierlo T, Prickaerts J (2014) Improvement of spatial memory function in APPswe/PS1dE9 mice after chronic inhibition of phosphodiesterase type 4D. Neuropharmacology 77:120-130. CrossRef Medline

Snyder JS, Soumier A, Brewer M, Pickel J, Cameron HA (2011) Adult hippocampal neurogenesis buffers stress responses and depressive behaviour. Nature 476:458-461. CrossRef Medline

Soltys Z, Ziaja M, Pawlínski R, Setkowicz Z, Janeczko K (2001) Morphology of reactive microglia in the injured cerebral cortex: fractal analysis and complementary quantitative methods. J Neurosci Res 63:90-97. CrossRef Medline

Steru L, Chermat R, Thierry B, Simon P (1985) The tail suspension test: a new method for screening antidepressants in mice. Psychopharmacology 85:367-370. CrossRef Medline

Tian DS, Xie MJ, Yu ZY, Zhang Q, Wang YH, Chen B, Chen C, Wang W (2007) Cell cycle inhibition attenuates microglia induced inflammatory response and alleviates neuronal cell death after spinal cord injury in rats. Brain Res 1135:177-185. CrossRef Medline

Wannier T, Schmidlin E, Bloch J, Rouiller EM (2005) A unilateral section of the corticospinal tract at cervical level in primate does not lead to measurable cell loss in motor cortex. J Neurotrauma 22:703-717. CrossRef Medline

West MJ, Slomianka L, Gundersen HJ (1991) Unbiased stereological estimation of the total number of neurons in thesubdivisions of the rat hippocampus using the optical fractionator. The Anatomical Record 231: 482-497. CrossRef Medline 
Wu J, Stoica BA, Faden AI (2011) Cell cycle activation and spinal cord injury. Neurotherapeutics 8:221-228. CrossRef Medline

Wu J, Pajoohesh-Ganji A, Stoica BA, Dinizo M, Guanciale K, Faden AI (2012a) Delayed expression of cell cycle proteins contributes to astroglial scar formation and chronic inflammation after rat spinal cord contusion. J Neuroinflammation 9:169. CrossRef Medline

Wu J, Stoica BA, Dinizo M, Pajoohesh-Ganji A, Piao C, Faden AI (2012b) Delayed cell cycle pathway modulation facilitates recovery after spinal cord injury. Cell Cycle 11:1782-1795. CrossRef Medline

Wu J, Kharebava G, Piao C, Stoica BA, Dinizo M, Sabirzhanov B, Hanscom M, Guanciale K, Faden AI (2012c) Inhibition of E2F1/CDK1 pathway attenuates neuronal apoptosis in vitro and confers neuroprotection after spinal cord injury in vivo. PLoS One 7:e42129. CrossRef Medline

Wu J, Renn CL, Faden AI, Dorsey SG (2013a) TrkB.T1 contributes to neuropathic pain after spinal cord injury through regulation of cell cycle pathways. J Neurosci 33:12447-12463. CrossRef Medline

Wu J, Raver C, Piao C, Keller A, Faden AI (2013b) Cell cycle activation contributes to increased neuronal activity in the posterior thalamic nucleus and associated chronic hyperesthesia after rat spinal cord contusion. Neurotherapeutics 10:520-538. CrossRef Medline
Yoon EJ, Kim YK, Shin HI, Lee Y, Kim SE (2013) Cortical and white matter alterations in patients with neuropathic pain after spinal cord injury. Brain Res 1540:64-73. CrossRef Medline

Zhang B, Huang Y, Su Z, Wang S, Wang S, Wang J, Wang A, Lai X (2011) Neurological, functional, and biomechanical characteristics after highvelocity behind armor blunt trauma of the spine. J Trauma 71:1680-1688. CrossRef Medline

Zhang HT, Huang Y, Masood A, Stolinski LR, Li Y, Zhang L, Dlaboga D, Jin SL, Conti M, O’Donnell JM (2008) Anxiogenic-like behavioral phenotype of mice deficient in phosphodiesterase 4B (PDE4B). Neuropsychopharmacology 33:1611-1623. CrossRef Medline

Zhao P, Waxman SG, Hains BC (2007) Modulation of thalamic nociceptive processing after spinal cord injury through remote activation of thalamic microglia by cysteine cysteine chemokine ligand 21. J Neurosci 27:88938902. CrossRef Medline

Zhao Z, Loane DJ, Murray MG 2nd, Stoica BA, Faden AI (2012) Comparing the predictive value of multiple cognitive, affective, and motor tasks after rodent traumatic brain injury. J Neurotrauma 29:2475-2489. CrossRef Medline 